Please do not remove this page

RMIT

UNIVERSITY

\title{
Pin pull-out behaviour for hybrid metal-composite joints with integrated reinforcements
}

Nguyen, Alex Thanh Trieu; Brandt, Milan; Feih, Stefanie; Orifici, Adrian

https://researchrepository.rmit.edu.au/esploro/outputs/9921860056701341/filesAndLinks?institution=61RMIT_INST\&index=null

Nguyen, A. T. T., Brandt, M., Feih, S., \& Orifici, A. (2016). Pin pull-out behaviour for hybrid metal-composite joints with integrated reinforcements. Composite Structures, 155, 160-172.

https://doi.org/10.1016/j.compstruct.2016.07.047

Document Version: Accepted Manuscript

Published Version: https://doi.org/10.1016/j.compstruct.2016.07.047

Repository homepage: https://researchrepository.rmit.edu.au

(C) 2016 Elsevier Ltd. All rights reserved

Downloaded On 2023/04/27 00:51:06 +1000

Please do not remove this page 
Thank you for downloading this document from the RMIT Research Repository.

The RMIT Research Repository is an open access database showcasing the research outputs of RMIT University researchers.

RMIT Research Repository: http://researchbank.rmit.edu.au/

\section{Citation:}

Nguyen, A, Brandt, M, Feih, S and Orifici, A 2016, 'Pin pull-out behaviour for hybrid metal-composite joints with integrated reinforcements', Composite Structures, vol. 155, pp. 160-172.

See this record in the RMIT Research Repository at:

https://researchbank.rmit.edu.au/view/rmit:38052

Version: Accepted Manuscript

Copyright Statement: (c) 2016 Elsevier Ltd. All rights reserved This work is licensed under a Creative Commons Attribution 4.0 International License.

Link to Published Version: 


\section{Pin pull-out behaviour for hybrid metal-composite joints with integrated reinforcements}

Alex T.T. Nguyen ${ }^{1}$, Milan Brandt ${ }^{1}$, Stefanie Feih $^{2,3}$ and Adrian C. Orifici ${ }^{2 *}$

${ }^{1}$ Additive Manufacturing Research Centre, School of Engineering, RMIT University, Melbourne, Victoria 3001, Australia

${ }^{2}$ Sir Lawrence Wackett Aerospace Research Centre, School of Engineering, RMIT University, Melbourne, Victoria 3083, Australia

${ }^{3}$ Joining Technology Group, Singapore Institute of Manufacturing Technology (SIMTech), 138634, Singapore

Submitted to Composite Structures

\footnotetext{
*Corresponding author: adrian.orifici@rmit.edu.au
} 


\section{ABSTRACT}

Hybrid metal-composite joints that integrate pins on the metal adherend are a novel joining concept, and knowledge regarding single pin performance and correlation to multi-pin joint behaviour is critically lacking. Here, we investigate Selective Laser Melting manufactured Titanium adhered with pins to carbon fibre-reinforced polymer composite. Single pin specimens under pull-out loading and Mode I crack growth specimens were investigated using experimental, finite element (FE) and analytical methods. We found the pin-composite interfacial strength was 3.5 times higher than comparable carbon fibre z-pins due to excellent adhesion characteristics of the as-manufactured pin surface. Consequently, the pins enabled a $365 \%$ increase in Mode I steady-state fracture toughness. We also determined that the enhanced bonding increased the maximum pin load and Mode I initiation fracture toughness by around $250 \%$, with no pin-composite debonding during cure. We lastly show FE models using the pull-out response characterised in single pin tests give excellent predictions of experimental behaviour in multi-pin joints with no additional calibration. The work provides new correlation between pin behaviour in isolation and in multi-pin joints, highlights the importance of strong pin-composite adhesion for joint performance, and demonstrates an analysis methodology suitable for design of pin-reinforced composites and metal-composite hybrid joints. 


\section{INTRODUCTION}

With the increasing adoption of carbon fibre-reinforced polymer (CFRP) composites in many industry sectors as a replacement for metallic components, the use of hybrid metalcomposite joints is becoming more common, and the need to optimise the connection between dissimilar materials is a key challenge. Current joining practice of dissimilar materials is generally limited to the use of metallic fasteners, such as in the case of trailing edge devices or the metallic hinge bolted to CFRP composite panels on the Airbus A330 undercarriage door. Figure 1a illustrates a typical bolted joining process of a metallic hinge with CFRP composite panel. However, bolted connections are problematic due to stress concentrations, mismatch in thermal expansion and resulting fatigue issues $(1,2)$, thus often limiting the potential material selection.

A recent development in hybrid metal-composite joints is the use of through-thickness reinforcement (pins) in the composite (3-11), which is commonly enabled by advanced manufacturing techniques. A recent study by the authors (12) has shown that rather than adding surface features as a separate manufacturing step (as shown in several publication (5-7, 9)), features can be produced during the manufacturing process of the metallic adherend using selective laser melting (SLM). Figure $1 \mathrm{~b}$ illustrates the assembly of a metallic hinge integrated with through-thickness pins. The surface pins can be included during the SLM part manufacture. A similar concept was previously studied with two-step manufacturing techniques such as cold-metal-transfer (9), laser treatment process (4) and selective sintering (5-7). This novel integrated design concept has not yet been demonstrated for SLM reinforcement pins in hybrid metal-composite joints, hence all aspects of this new joining technique need to be understood. Critically, knowledge is needed on the manufacturing processes and the effect on the subsequent joint properties, the performance of a single pin as 
it is pulled out of the composite, and the performance of a multi-pin joint where pins are pulled out.

Previous publications on hybrid metal-composite joints with through-thickness reinforcements provide some insight into the expected performance of the proposed joint concept. In single and double lap shear experiments, straight cylindrical reinforced pins have shown a major increase in strength and strain to failure $(3,9)$ in comparison with unpinned adhesive joints. Various pin tip features have been studied including ball head (9), conical head $(6,7,11)$ and triangular tip (10), and shown to further increase joint performance. Damage mechanisms observed include pin-composite interface failure, pin fracture, plastic deformation of the pins and composite damage. However, all previous studies have focused on joint performance in shear, whereas tension (pin pull-out) can be more critical in many applications and typically involves lower strength and toughness. Further, previous studies have not yet identified the critical link of single pin performance and multi-pin joint properties. Additionally, we lack an understanding of how geometry parameters and interface properties relate to pin performance and failure mode. This information is critical not only for the specific joint design being considered, but also in terms of understanding how this category of hybrid joints performs and can be analysed, predicted and optimised.

Much can be understood regarding through-thickness reinforcement of composites from the significant body of knowledge in z-pin reinforcements (13). Previous studies on reinforcing composite materials with CFRP and more recently metallic z-pins have covered a wide range of aspects including the effect of pin insertion on the composite microstructure, the performance and failure modes of single pins and multi-pin laminates under various loadings, and analytical and computational methods for single pin and multi-pin laminate analysis. However, further studies on the critical aspects of pin alignment and surface 
bonding are needed to make these results more broadly applicable, as previous work was driven by the inherent nature of the z-pins studied to date.

Firstly, CFRP z-pins are generally characterised by a misalignment angle on average of $14^{\circ}$ between the pins and the through-thickness direction (14-16), which among other factors leads to "snubbing" or friction as the pin is pulled out. This has prevented accurate understanding and characterisation of pins under pure pull-out loading, and similarly has affected attempts to link single-pin behaviour to multi-pin joints. In contrast, the significant body of knowledge on steel-reinforced concrete has shown characterisation of steel reinforcements under pure pull-out loading (17-21), but analytical models incorporating this behaviour are then not applied to analyse multi-pin joints, and the nature of the steel-concrete interface and scale of the reinforcement make those results less applicable for this research.

Secondly, CFRP and extruded metallic z-pins typically exhibit very low interface strength due to poor pin-composite bonding, which significantly affects joint performance. As a result, the mismatch in thermal expansion coefficient (CTE) between pin and composite leads to significant debonding at the pin-composite interface from curing in manufacture (22, 23), and z-pins are understood to only be effective in providing bridging traction after they have begun to pull out (24). Consequently, the performance of through-thickness composite reinforcement with high pin-composite interfacial shear strength has not been studied. This is important as the SLM titanium-composite interface produced in this work is shown to have excellent intrinsic adhesion properties, with the as-manufactured metal surface providing similar strength to specimens with best-practice (and costly) surface preparation techniques (12).

In this study, the performance of reinforcements in hybrid SLM metal-CFRP composite joints is investigated in single pin specimens and multi-pin joints. Straight single 
pin specimens of varying pin geometry (length and diameter) are used to characterise the composite microstructure and metallic component geometry and material in the manufactured joint. These specimens are then experimentally tested in tension (loading along the pin axis) to study and characterise in isolation the adhesion response of a single pin as it is pulled out of the composite. Double Cantilever Beam (DCB) specimens in unpinned and pinned configurations (with pins in rows) are tested experimentally and analysed with finite element (FE) models. We clearly establish for the first time the correlation between the single pin pull-out and the pin pull-out in multi-pin joints, both in terms of the failure modes and failure energy. This novel work includes applying an analytical model for pin pull-out behaviour that is empirically characterised from the single pin tests to the FE models of the DCB specimens with no further adjustment or calibration required. Comparison to typical CFRP z-pin properties is provided where applicable to highlight the influence of pin alignment and enhanced surface bond between pin and composite.

\section{EXPERIMENTAL METHODOLOGY}

\subsection{Single pin pull-out test}

Single pin specimens were designed involving a square platform and central throughthickness pin (Figure 2). A test setup was developed to apply tension (pull-out) loading to pull the metal and composite adherends apart along the pin axis (Figure 2). The composite adherend used unidirectional pre-preg tape layers of T700 carbon/epoxy plies (VTM264, Advanced Composites Group). A polytetrafluoroethylene (PTFE) insert of $0.1 \mathrm{~mm}$ thickness was used at the interface of the titanium adherend and the composite as a pre-crack (see

Figure 2). This allowed for the exclusive study of the pull-out response of the pin, as the adhesion properties between the two materials were characterised previously (12). 
To manufacture the joint, the plies were first laid up into sub-laminates of four layers and de-bulked, and each sub-laminate was then pressed onto the pin using manual pressure until the composite and metal parts were in contact. The process was repeated until the thickness of the composite adherend was equal to the total length of the pin. The whole system was co-cured in an autoclave according to manufacturer recommendations for the composite $\left(120^{\circ} \mathrm{C}, 620 \mathrm{kPa}, 1\right.$ hour $)$.

After curing, aluminium tabs were adhesively bonded to the adherends. The tabs were connected to a double lap joint that used a single bolt on each side of the joint, and the end of the joint was clamped in the test machine. The double lap joint was loosely bolted to secure the joint with only minimal bolt torque, which allowed for slight movement and rotation of the configuration under loading. This was found to be necessary so that the test setup could self-adjust under loading, to prevent damage to the specimen from any misalignment between the pin axis, tabs and test machine loading axis. The specimens were loaded with a monotonically increasing opening displacement at a rate of $0.5 \mathrm{~mm} / \mathrm{min}$. Four different specimen configurations were investigated, as shown in Table 1, involving three variations in total pin length and two variations in pin diameter $(D)$, with three specimens per configuration tested. For the thick pin specimens ( $1 \mathrm{~mm}$ diameter), 5 specimens were tested. Given the chamfer of the pin, and the definition of pin length $(L)$ being to the bottom of the chamfer (see Figure 2), using the same pin total length for thin and thick pins resulted in a different pin length $L$ for the same composite thickness.

\subsection{Double cantilever beam hybrid joints}

Double Cantilever Beam (DCB) specimens (ASTM D5528-13 (25)) were used to study the crack growth in the hybrid joint specimens under Mode I (opening) loading, as shown in Figure 3. A similar pin insertion and joint manufacturing process as for the single 
pin specimen was used. Three different specimen configurations were investigated, as shown in Table 1, with an unpinned specimen and two configurations of varying pin length, and three specimens per configuration tested. The pin diameter was $0.5 \mathrm{~mm}$ for all specimens and the pin volume content was nominally set to $0.5 \%$ by using a spacing between pins of 6.27 $\mathrm{mm}$. The first row of pins was placed at the end of the pre-crack region (start of the bonded region). The thickness of the composite adherend in the unpinned specimen was set to match the bending stiffness of the metal adherend. For the pinned configurations, the composite adherend thickness was controlled by the pin total length, and an additional composite laminate was bonded to the metal adherend so that the bending stiffness of both cantilever arms was equal. The thickness of the composite reduced by up to $0.1 \mathrm{~mm}$ on average due to resin bleed in curing, though this was considered to have minimal effect on fracture toughness, and the as-manufactured thickness was used in numerical models.

A monotonically increasing opening displacement was applied at a rate of $2 \mathrm{~mm} / \mathrm{min}$ to aluminium tabs bonded onto the pre-cracked end of the DCB specimen. The crack length was measured throughout the test using a travelling optical microscope. The Mode I interlaminar fracture toughness $\left(G_{\mathrm{Ic}}\right)$ was calculated using the modified beam theory method according to the test standard (25):

$$
G_{\text {Ic }}=\frac{3 P \delta}{2 b(a+\Delta a)}
$$

Equation 1

where $P$ is the applied load, $\delta$ is the opening displacement, $b$ is the specimen width, $a$ is the crack length and $\Delta a$ is a correction factor determined from test compliance.

\subsection{SLM manufacturing}


Titanium components for single pin and DCB specimens were printed in a build chamber of $250 \mathrm{~mm} \times 250 \mathrm{~mm} \times 350 \mathrm{~mm}(\mathrm{SLM} 250 \mathrm{HL}$, SLM Solutions, Germany) using the same manufacturing parameters of previous work $(12,26,27)$ to achieve a low porosity level of less than $0.3 \%$ and an average surface roughness $\left(S_{a}\right)$ of $10 \mu \mathrm{m}$ (Alicona IF-EdgeMaster profilometer). Specimens were printed upright with an inclination angle of $20^{\circ}$ from the vertical axis to reduce thermal residual stresses in the part and to allow for printing of the overhanging pin structure without additional support material for a length of up to $4 \mathrm{~mm}$ per pin (28). Recent publications $(29,30)$ investigating the effect of build orientation on the mechanical properties of the same Ti-6Al-4V material reported approximately $4 \%$ reduction in ductility and no effect on stiffness and strength when the build orientation was changed from vertical to horizontal. As the pins were manufactured at $20^{\circ}$, it is expected that the pin strength and stiffness is similar to that of the bulk material with little reduction in ductility. In addition, Strano et al. (31) experimentally showed minimal change in surface roughness ranging from $12 \mu \mathrm{m}$ to $16 \mu \mathrm{m}$ with increasing build angle from $5^{\circ}$ to $90^{\circ}$ for a powder-based manufacturing process as particles inherently attach to the surface due to thermal dissipation. As there is no change in the roughness of the part, it is expected that the partially melted particles on the pin offer high adhesion performance as shown in a previous study by the authors (12).

A $45^{\circ}$ chamfer ( 1 diameter) was used at the tip of the pin to assist the later manual pushing of the composite laminates onto the pins. The manufactured parts were lightly tapped with an ultrasonic gun to vibrate the excess powder off and acetone was used to clean the part.

Detailed inspection of the manufactured pins revealed that the cross-sectional shape of the thinner pins $(D=0.5 \mathrm{~mm})$ varied significantly from being nominally circular. This is due to the partially melted particles attached to the bottom side of the pin as shown in Figure 
4a. This phenomenon has been previously observed for overhanging truss structures (28). Considering all results, the cross-sectional shape was found to be best approximated by an ellipse. The thicker pins $(D=1.0 \mathrm{~mm})$ were largely unaffected by this and the cross-section remained mostly circular. The major and minor diameters of the elliptical profile were measured for the single pin specimens at three locations along each pin, with four measurements taken at $90^{\circ}$ intervals around the pin at every location. At least three specimens were measured for each configuration, and the coefficient of variance (COV) was less than $4 \%$ for all sets of measurements. A summary of the average pin dimensions is shown in Figure $4 \mathrm{~b}$, where the profiles of the nominally $0.5 \mathrm{~mm}$ and $1.0 \mathrm{~mm}$ pins are overlaid. The pin cross-sectional area and circumference from the ellipse of best fit was taken into account when calculating the pin strength and interface strength. The difference between the nominal (design) and actual manufactured pin dimensions meant that the actual $L / D$ ratio varied for each configuration, in some cases significantly, which is further discussed in the results section where the nominal and actual $L / D$ ratios are presented. For the DCB specimens, another effect of the cross-section change was an increase of the pin volume content from $0.5 \%$ to $0.74 \%$ for the $0.5 \mathrm{~mm}$ diameter pin and $0.55 \%$ for the $1.0 \mathrm{~mm}$ diameter pin.

The pins were found to contain a small amount of internal porosity along their length as shown in Figure 4c. The maximum diameter of the internal porosity varied from $30 \mu \mathrm{m}$ to $200 \mu \mathrm{m}$. The location of the largest pore was stochastic in nature along the pin length, though the majority of the pores was found to be located on the finishing side (see Figure 4a) of the pin. This type of surface porosity is expected to reduce the tensile strength of the pin as compared to that of the bulk material due to the small diameter and proximity of pores to the tensile surface stresses. Another inherent defect found for the SLM pins was the potential reduction in diameter at the pin root. This is thought to be due to heat dissipating into the 
large base of the component leading to a smaller melt pool. A small fillet of $0.5 \mathrm{~mm}$ radius was found to mitigate this defect effectively and was introduced for all pins studied in this work.

Despite these aspects, the overall dimensional tolerance of the SLM-manufactured components was very high, with an expected tolerance of $0.1 \mathrm{~mm}$ for all dimensions. The pin axis of the specimen is straight and the misalignment angle is estimated to be $0^{\circ}$ following insertion into the CFRP composite adherend in contrast to typical values of $14^{\circ}$ for CFRP zpins (22).

\section{ANALYSIS METHODOLOGY}

A numerical modelling approach is developed to predict the performance of an arbitrary multi-pin hybrid joint by superposing discrete fracture events due to single pin pullout with the continuous fracture of the unpinned interface (see Figure 5). The single pin pullout test is used to identify the parameters for an analytical pull-out law or stress-displacement behaviour for the discrete distribution of non-linear springs as outlined in Section 3.1. Separately, an unpinned specimen in DCB configuration is characterised to determine the mechanisms associated with the unpinned adhesion properties. Two continuous crack growth contributions in the form of matrix fracture and fibre bridging are identified and implemented via cohesive elements on the interface as described in Section 3.2. No additional adjustment or calibration of parameters is undertaken for the pinned DCB model.

\subsection{Analytical bridging laws}

For the single pin specimens, pulled out pins show failure (loss of load-carrying capability or maximum load) either from pin-composite interface failure in shear or pin fracture in tension. It is assumed that the pin is perfectly embedded in the surrounding 
material, and that the PTFE layer (see Figure 2a) prevents any contact (load transfer) between metal and composite parts except for at the pin-composite interface. As such, the load path between adherends involves all load carried in the pin-adherend interface and in the pin itself. The interfacial shear stress $\tau_{\max }$ at maximum load $P_{\max }$ can be determined using the pinadherend contact area, and is given by

$$
\tau_{\max }=\frac{P_{\max }}{C_{e}\left(L-\Delta_{0}\right)}
$$

where $C_{e}$ is the pin circumference from the averaged measured ellipse (Figure $4 \mathrm{~b}$ ), and $\Delta_{0}$ is the pin pull-out displacement at $P_{\max }$ (which reduces the interface contact area). Separately, the axial tensile stress $\sigma_{\max }$ in the pin at maximum load is determined from

$$
\sigma_{\max }=\frac{P_{\max }}{A_{e}}
$$

where $A_{e}$ is the pin cross-sectional area from the averaged measured ellipse (Figure $4 \mathrm{~b}$ ). For specimens that fail (at $P_{\max }$ ) due to interfacial shear failure, Equation 2 is used to determine the interface strength. For specimens that fail in pin fracture, Equation 3 is used to determine the pin tensile strength.

The transition between the two failure modes is a function of pin strength, interface strength and geometrical parameters. At the transition point, both failure modes are occurring at the same load. Combining Equation 2 and Equation 3, an expression can be derived to define the transition aspect ratio $L / D$ of the pin:

$$
\frac{L}{D}=\frac{\sigma_{\max }}{4 \tau_{\max }}
$$


Equation 4 shows that the transition aspect ratio is a function of only the relative strengths of the pin and interface, and that pins with aspect ratio greater than the transition value will fail in pin fracture.

A single pin "pull-out law" in defined in this study through the relationship between the interface stress $\tau$ and the pull-out displacement $\Delta$, as given by

$$
\tau(\Delta)=\tau_{\max } \exp \left[-\alpha\left(\frac{\Delta-\Delta_{0}}{L}\right)^{\beta}\right]
$$

where $\tau_{\max }$ and $\Delta_{0}$ are obtained from experimental data and the two dimensionless parameters $\alpha$ and $\beta$ are curve-fit to experimental data. The pull-out load $P(\Delta)$ is then determined from

$$
P(\Delta)=\tau(\Delta) C_{e} x(\Delta)
$$

where $x$ is the embedded length of the pin as defined in Equation 7 by Lee et al. (20) such that the pull-out displacement $\Delta$ varies from $\Delta_{0}$ to $L$ while $x$ varies from $L$ to 0 :

$$
x(\Delta)=\frac{L}{L-\Delta_{o}}(L-\Delta)
$$

The pull-out displacement data from the test machine needed to be adjusted to account for machine compliance, as this directly affected the values for $\Delta_{0}$ and failure energy. In this work, the machine compliance was determined as approximately $0.00075 \mathrm{~mm} / \mathrm{N}$, $0.0006 \mathrm{~mm} / \mathrm{N}$ and $0.00045 \mathrm{~mm} / \mathrm{N}$ for the $2 \mathrm{~mm}, 3 \mathrm{~mm}$ and $4 \mathrm{~mm}$ pin specimens, respectively. The displacement data was corrected using a method similar to that presented in Ref. (32).

The failure energy $E$ of a single pin (associated with either the pull-out process or pin fracture) can be calculated by integrating Equation 6 over the pull-out displacement or can be 
estimated from experimental data using the area under the traction load versus pull-out displacement curve. To correlate between the failure energy of the pull-out specimens and the fracture toughness observed in multi-pin joints, the following equation is used:

$$
G_{\text {pin }}=V_{p} \frac{E}{A_{e}}
$$

where $G_{p i n}$ is the contribution of the pins to the fracture toughness of the joint (as other mechanisms exist that also provide fracture toughness) and $V_{p}$ is the volume fraction of pins in the joint.

\subsection{Finite element model}

While semi-analytical approaches are available to analyse DCB results with pull-out events $(33,34)$, finite element modelling provides a more flexible framework to capture the response of pin-reinforced composite structures. Three-dimensional models of the DCB specimens were developed in Abaqus/Standard 6.12, and they incorporate both material and geometric non-linearity. The key aspects of the numerical DCB model are summarised in Figure 6, and the material properties are shown in Table 2. The loading tabs were coupled with the adherends in all degrees of freedom (DOF) and pulled apart using displacement control. Three different mechanisms occur during crack propagation process and are captured separately through the use of either continuous cohesive elements at the interface (fibre bridging, resin fracture) or discrete spring elements to model every pin individually.

To capture progressive crack growth in a continuous manner, a pre-defined crack path was modelled by embedding zero thickness cohesive elements (COH3D8) (35) along the interface of the titanium and the composite adherend (see Figure 6). The pre-crack region was modelled without any cohesive elements. The typical length of all interface cohesive 
elements along the crack path was kept consistently at $0.05 \mathrm{~mm}$ and the penalty stiffness $K$ was determined using (36)

$$
K=\beta_{p} \frac{E_{33}}{t}
$$

where $E_{33}$ is the adherend through-thickness elastic modulus, $t$ is the adherend thickness, and $\beta_{p}$ is a parameter used to set the penalty stiffness. A $\beta_{p}$ value of 10 was found to provide reasonable penalty stiffness, which is large enough for an interface stiffness and small enough to reduce the risk of numerical problems such as spurious oscillations of the tractions in an element (36).

The basic adhesion properties of the unpinned specimen including resin fracture and fibre bridging need to be considered first as outlined in detail in a previously published study by the authors for the same material system (12). The numerical procedure uses two superposed cohesive elements at the same location to capture the two simultaneous damage mechanisms of resin fracture and fibre bridging. Essentially, the first cohesive element with high strength and low toughness is used to represent the resin fracture at the crack front, while the second cohesive element with low strength and high toughness is used to represent the fibre bridging mechanism. The respective material property values are shown in Table 3 . The use of cohesive elements treats these two damage events as simultaneously occurring continuous processes along the length of the DCB specimen.

The additional discrete bridging traction mechanism of the pins during the pull-out process can be modelled using non-linear springs $(24,37,38)$ or cohesive elements $(39-41)$. In this study, non-linear springs were used as the analytical bridging laws derived from equations in Section 3.1 can be directly input into the model as discrete spring properties 
(SPRINGA) (35) at the actual location of each metal pin, hence resulting in discrete toughness contributions rather than a continuous process.

\section{RESULTS AND DISCUSSION}

\subsection{Composite micro-structure surrounding pin inserts}

The disruption to the composite micro-structure caused by inserting the throughthickness SLM pins was similar to that seen for CFRP z-pins (see for example the work of Chang et al. (13)). Figure 7a shows a schematic of the typical alteration in in-plane crosssectional profile that was characterised by localised fibre waviness, broken fibres and a resinrich zone. In all cases, the localised fibre waviness region is defined by the horizontal lengths $H_{3}$ and $H_{4}$ and vertical length $V_{1}$ and $V_{2}$ (Figure 7a). These parameters were found to be symmetric and a function of the pin dimension in the same direction, such that $H_{3}=H_{4}=$ $3.5 D_{h}$ and $V_{1}=V_{2}=3 D_{v}$ for all pin sizes. The fibre waviness confined within the region of $V_{1}$ and $V_{2}$ reduced linearly from a maximum around the pin to zero at the length $V_{2}$. The resinrich zone was formed in the region between the broken fibres and the pin as shown in Figure 7. The horizontal length of the resin-rich zone is defined by $H_{1}$ and $H_{2}$, and it was found that $H_{1}=H_{2}=3 D_{h}$.

Additionally, the pin insertion process altered the through-thickness cross-section of the composite, which was distinguished by fibre crimp, fibre breakage and a resin-rich zone parallel to the fibres as shown in Figure $7 \mathrm{~b}$. The act of fibre crimping led to formation of a resin-rich zone defined by distances $C_{1}$ and $C_{2}$ (refer to Figure $7 \mathrm{~b}$ ) which were found to be equal and approximately 2.5 times the diameter $D_{h}$ parallel to the fibre direction. The fibre crimp diminished linearly toward the tip of the pin. No resin-rich zone was found in the through-thickness cross-section perpendicular to the fibres (Figure 7c), as in this direction the 
fibres did not crimp and simply moved laterally as the pin was pushed through in manufacture.

Previous studies on CFRP z-pin reinforcement have reported interfacial cracking due to the mismatch between the thermal expansion coefficient of the pin and the adjacent resinrich zone. Sweeting and Thomson (23) have shown in-plane thermal-induced interface cracking and Mouritz (22) further showed partial interfacial cracking along the throughthickness direction. In this work, no interfacial cracking was found at the in-plane crosssection (Figure 8a) and through-thickness cross-section (Figure 8b) for all specimens despite the similar interruption of fibre network. The fact that there is no visible thermal crack despite the mismatch in thermal expansion coefficient between the titanium pins and the surrounding material demonstrates the significant strength of the pin-composite interface, which is attributed to the partially melted particles that are attached on the surface of the pin. Our previous study (12) has shown that these particles enhance the interface strength through an increase in surface area and through mechanical interlocking.

\subsection{Pull-out response of single SLM pins}

The experimental results of the single pin specimens under pull-out loading are presented in Figure 9 and Table 4, where Figure 9 presents the traction load versus pull-out displacement results, and Table 4 summarises all calculated results based on the previously provided analytical expression. It should be noted that the increase in total circumference of the pins due to the partially melted particles was taken into consideration in the presented results as per Equation 2 and measured $C_{e}$ values as provided in Table 4. For Figure 9, a single test result is presented that is most representative of the average result for each configuration. In Table 4, results for the coefficient of variance are also included, and although in most instances this is calculated from only three data points it is still considered a 
reasonable indication of the variance in the results. For the purpose of comparison, an "actual" $L / D$ is provided in Table 4, where the diameter was taken from the average of the major and minor diameters of the elliptical profile. For one test $(D=0.5, L=3)$, displacement data was considered unreliable from the test, so the $\Delta_{0}$ and failure energy values were excluded as outliers. Good repeatability was seen across all results, with variance between $4 \%$ and $15 \%$ for maximum load and failure energy across all specimens (except one configuration where the variance on failure energy was $38 \%$ ), and no inconsistencies in failure mode were observed for any configuration.

Overall, the results demonstrate that the SLM metal-composite hybrid joint system performed in a similar manner under pull-out loading to CFRP z-pins reported in literature (42). Low aspect ratio pins $(D=0.5, L=2$ and $D=1.0, L=3.5)$ were shown to lead to pincomposite interface failure in shear whereas higher aspect ratio pins $(D=0.5, L=3$ and $D=0.5$, $L=4$ ) led to pin fracture in tension. Using the average of the $\sigma_{\max }$ and $\tau_{\max }$ values in Table 4 with Equation 4 produces a transition aspect ratio of $L / D=3.6$, which agrees well with the observed transition between specimens with modified aspect ratios of 3.3 and 5.0. The energy absorbed in interface failure was significantly higher than in pin fracture, with more than 5 times the absorbed energy for the same pin diameter.

The average interface stress from the two configurations showing interface failure was $48 \mathrm{MPa}$. The higher interfacial strength is closely related to the partially melted particles existing at the surface of the SLM pin. During the co-curing process, the ridges between the particles provide a mechanical interlocking effect in addition to increasing the surface area of the bond. This in turn enhances the load-carrying ability of the interface and promotes adhesive or adherend failure, as the crack progresses through the adhesive or composite resin and either diverts around or shears through the titanium particles. This was seen in 
microscopy images of the pins following interface failure, which showed the surface covered with adhesive and partially melted particles (Figure 10a). Further, computed tomography (CT) scans of the pin cavity in the composite adherend after pin pull-out revealed a large amount of partially melted titanium particles still attached to the surface of the epoxy resin (Figure 10b). The pin fracture mode also demonstrated behaviour that is characteristic of SLM material components. Figure 11 shows typical pin fracture damage. The average tensile strength from the two configurations showing pin fracture was $725 \mathrm{MPa}$, which is significantly lower than the bulk material strength of $1028 \mathrm{MPa}$ previously reported (26). Pin fracture was also seen to occur close to the pin root. As such, failure stresses for the pins were lower than the bulk material strength due to the combined effects of stress concentrations at the root during pull-out and random distribution of porosity size and location in the vicinity of the root.

\subsection{Single pin pull-out law}

Using the analytical pull-out law of Equation 5, values of $\alpha=5.75$ and $\beta=1.55$ were found to provide suitably close prediction for the pull-out response of both configurations, as shown in Figure 12. In this figure, the displacement data was normalised using the pin length so that the results from the two configurations can be easily compared. These results show that the pull-out law represents the behaviour of both pins very well, with any deviation within experimental variance. Analytical predictions of failure energy were $91 \mathrm{~J}$ and $473 \mathrm{~J}$ for thin pins $(D=0.5, L=2)$ and thick pins $(D=1.0, L=3.5)$, respectively. These values are within $9 \%$ of experimental values and of the order of the experimental variance of the test data.

The typical pull-out stress-displacement curve of a CFRP z-pin of $0.28 \mathrm{~mm}$ thickness and $4 \mathrm{~mm}$ length is indicated for comparison in Figure 12 (42). One key aspect in the results that differs from published z-pin results is the exponential shape of the load-displacement 
curve, as evidence that the interface failure mode was characterised in isolation. Typically, carbon and metallic z-pin reinforcements exhibit linear load-displacement behaviour during pull-out $(14,16,33,40,43-46)$. This can be attributed to a large degree of misalignment in the pins, typically $12^{\circ}$ to $15^{\circ}$, which introduces a "snubbing" or crushing damage mechanism that acts in addition to the interface failure (13). In contrast, studies of steel bar reinforcement in concrete have widely reported exponential pull-out behaviour, where the interface properties degrade from the abrasion of the pull-out process (17-21). As such, the results in this study provide the first evidence that despite the different scales involved, the interface failure of micro-scale through-thickness reinforcements is governed by the same mechanisms as for steel-reinforced concrete. Further, the observation of exponential pull-out behaviour confirms that the interface failure was characterised for straight pull-out without additional damage modes such as snubbing, which could have been present if the test setup did not selfadjust.

Another significant difference to published z-pin results for metallic or carbon reinforcements is the much larger interface strength of $48 \mathrm{MPa}$, which is caused by the excellent adhesion between the SLM surface and composite as explained previously. This is much higher than the typical interfacial strength of around $15 \mathrm{MPa}$ reported in comparable studies of CFRP z-pin reinforcement $(14,40,42)$, which is shown in Figure 12. Additionally, the combination of residual thermal cracks along the CFRP/composite interface as well as the inherent misalignment angle of the pin causes the stiffness of the CFRP z-pin to be much lower than for the hybrid system investigated here.

It should finally be noted that the low pin strength and high interface strength reduce the transition aspect ratio of SLM pins to below 4 (see Eq. 4), which in comparison was experimentally established as approximately 20 for CFRP pins (42). 
The close comparison between the experimental and analytical results indicates that the characterised pull-out law is independent of pin geometry and can therefore be used for design and optimisation studies. For example, Figure 13 shows the effect of increasing pin volume content on DCB specimens with $L=2 \mathrm{~mm}$ pins of increasing diameter from $0.55 \mathrm{~mm}$ to $2.0 \mathrm{~mm}$. The results indicate that the steady-state fracture toughness increases linearly with increasing pin volume content for all pin sizes. Additionally, for the same pin content, the toughness value decreases exponentially with increase in pin diameter, which becomes more prominent with higher pin content. Essentially, when the pin aspect ratio moves away from the transition aspect ratio, the pins become less effective at absorbing energy. This is because thinner pins generate higher traction loads per unit crack area than thicker pins (47). Thus, it is essential to design the pin with the $L / D$ aspect ratio smaller than the transition aspect ratio to ensure pin-composite interface failure occurs. However, the $L / D$ aspect ratio should be close to the transition aspect ratio to ensure effective energy absorption.

\subsection{Mode I crack growth behaviour of pin-reinforced hybrid joints}

Load-displacement and R-curve (fracture toughness versus crack length) results for the DCB specimens are shown in Figure 14 for the unpinned specimen and the pinned specimen with actual pin aspect ratios of $3.3(D=0.5, L=2)$ and $6.5(D=0.5, L=4)$, see Table 4 . Additionally, the steady-state fracture toughness of a typical CFRP z-pin $(D=0.5, L=2)$ is included in Figure 14b to compare the effectiveness of the two different reinforcement systems. The DCB specimen with longer pins (actual aspect ratio 6.5) showed pin fracture with lower fracture toughness, which agrees well with the transition aspect ratio established in the single pin specimens, and demonstrates that pins show equivalent behaviour in the single pin and DCB specimens. 
From the results in Figure 14, the overall adhesion response of the unpinned specimen can be characterised by crack initiation at an initial fracture toughness of $0.2 \mathrm{~kJ} / \mathrm{mm}^{2}$, a region of increasing fracture toughness as the fibre bridging process zone develops, and then steady-state crack propagation with a roughly constant fracture toughness of $1.0 \mathrm{~kJ} / \mathrm{mm}^{2}$ and fully developed bridging zone of approximately $30 \mathrm{~mm}$. The R-curve indicates that the contribution of fibre bridging to the fracture toughness is significant and much larger than the fracture toughness at crack initiation. This behaviour is captured well by the numerical simulation, which uses separately characterised cohesive elements for basic adhesion failure of the resin and fibre bridging.

Similar behaviour is seen for the pinned specimen, though the inclusion of the pins produced a significant increase in load-carrying capability and fracture toughness. The specimens with pins failing in pin-composite interface failure $(L / D=3.3)$ had a significantly higher fracture toughness than the DCB specimens with longer pins $(L / D=6.5)$. For the specimens showing interface failure and pin pull-out, the maximum load, fracture toughness at crack initiation and steady-state fracture toughness increased to $270 \%, 250 \%$ and $377 \%$ of the respective unpinned specimen values. Using the numerical model with non-linear springs for each pin, the load-displacement response and the increase in fracture toughness are again predicted very accurately, which reflects the accurate characterisation of the single pin behaviour. Comparatively, the fracture toughness of SLM pins is almost twice as high compared to similar CFRP z-pin configurations as indicated in Figure 14b. This is due to the significantly higher fracture energy associated with the pull-out process of SLM pins shown in Figure 12.

The mechanisms during crack propagation involve a combination of adhesion, fibre bridging, and pin traction leading to interface failure of low aspect ratio pins $(D=0.5, L=2.0)$ 
or pin fracture of high aspect ratio pins $(D=0.5, L=4.0)$ (see Figure 14b). As the crack opening displacement is applied, the first row of pins acts to provide a bridging traction. Under increasing opening displacement, the pins either start debonding or fracture, allowing the crack to propagate until it is arrested by the second row of pins. For high aspect ratio pins where pin fracture is seen, this process simply repeats with every row of pins.

For pins where interface failure is seen, the crack growth is accompanied by gradual pull-out of the pin, which absorbs a large amount of energy and is reflected in increasing Mode I fracture toughness. The process repeats to the third row of pins at which point maximum load is reached and the bridging zone along the crack length is fully developed as indicated in Figure 15. Following this, steady-state crack growth with stick-slip behaviour is seen, which is similar to the typical behaviour of z-pin reinforced CFRP composite $(13,24)$. The crack slips when a row of pins furthest away from the crack front is completely pulled out. This is usually reflected by a drop in load, which is regained when the crack advances and arrests at the next row of pins.

The failure energy of the single pin specimens also showed very good agreement with the fracture toughness of the DCB specimens. Using Equation 8, with the experimentally measured cross-sectional (elliptical) area, volume fraction and single pin failure energy, the pins are estimated to contribute $2.61 \mathrm{~kJ} / \mathrm{mm}^{2}$ to the DCB specimen steady-state fracture toughness. This compares very well (within $2 \%$ ) with the value of $2.65 \mathrm{~kJ} / \mathrm{mm}^{2}$ obtained by subtracting the steady-state fracture toughness from pinned and unpinned DCB specimens.

The numerical model captures the stick-slip phenomenon very well due to the discrete arrangement of non-linear springs. Numerically, the stick-slip condition between each pin row was also reflected in the R-curve. This is not possible to obtain by experiment as the crack propagation between pins is fast and only one crack length measurement per pin row is 
possible. Additionally, through the position of the crack front in the FE model and the corresponding fracture toughness, the process zone during crack propagation process was found to consist of 3 rows of pins, which also compares very well to experiment observations.

Lastly, previous studies on z-pin reinforcement have observed that the presence of pins does not improve the initiation fracture toughness. In this study, it was shown both experimentally and numerically that the crack growth initiation toughness in fact increases. This is due to the high interface strength of the SLM pin-composite interface. As previously discussed, CFRP z-pins have low interface strength, and there is also typically significant debonding around the pin created in manufacture due to thermal mismatch. As such, these pins only start to absorb energy after they have started to be pulled out. On the other hand, the strength of the SLM pin-composite interface means that the pins can contribute to resisting initial crack growth. To confirm this, a numerical analysis was conducted where the pin interface strength varied between $15 \mathrm{MPa}$ (typical of CFRP z-pin reinforcements) and 50 MPa (typical of SLM pin) shown in Figure 16. The analysis clearly demonstrated that the initiation fracture toughness increased from $0.32 \mathrm{~kJ} / \mathrm{mm}^{2}$ to $0.76 \mathrm{~kJ} / \mathrm{mm}^{2}$. In contrast, the initiation fracture toughness for pins with low interface strength is only $0.1 \mathrm{~kJ} / \mathrm{mm}^{2}$ higher than the unpinned value. This is within typical experimental variance and explains why such increases are difficult to observe experimentally for previous conducted studies with CFRP zpins $(48,49)$.

\section{CONCLUSIONS}

In this work, we successfully establish a correlation of single pin versus multi-pin pull-out characteristics for SLM pin-reinforced hybrid metallic/composite joints. Based on single pin tests for different pin geometries, the following important pin characteristics were 
derived: (1) the pin/composite interface bond strength, (2) the pin strength, (3) the pin pullout bridging law and (4) the geometric ratio $L / D$ to determine the transition point between pin pull-out and pin fracture. The transition aspect ratio is especially important for the design of multi-pin joints as pins become less effective at absorbing energy as the pin dimensions move away from the ideal aspect ratio. It was then verified experimentally and numerically that these single pin properties can be applied to predict the failure mode and the pin contribution to the steady-state fracture toughness of the DCB specimens.

The DCB tests showed that the integration of SLM pins (nominally $0.5 \%$ of specimen volume) increased the maximum load, initiation fracture toughness and steady-state fracture toughness by $270 \%, 250 \%$ and $377 \%$ respectively, provided pins were designed to pull out of the composite and not fracture. Finite element analysis of the DCB specimens utilised a modelling strategy in which resin fracture, fibre bridging and pin pull-out were separately characterised and applied within different elements in order to allow additional correlation between the pin properties and fracture toughness improvements as well as comparisons with traditional CFRP z-pins to be made.

We established that the significantly higher interface strength for SLM pins within CFRP material translated into an increase in initiation fracture toughness and similarly higher steady-state fracture toughness. On the other hand, the critical aspect ratio for SLM pin pullout is adversely affected by the high interface strength and is therefore much lower than for CFRP pins, which needs to be considered when designing joints with metallic SLM pins for optimum fracture toughness improvement. 


\section{Acknowledgements}

The authors acknowledge the efforts of Mr Aaron Pateras for manufacturing of SLM structures, Mr Robert Ryan for support during composite lay-up and curing, and Mr Peter Tkatchyk and Mr Julian Bradler for providing assistance during mechanical testing. One of the authors, A.T.T. Nguyen, acknowledges financial support through an RMIT PhD International $\mathrm{PhD}$ scholarship (RPIS). One of the authors, S. Feih, acknowledges the support of the Agency for Science, Technology and Research and Engineering Research Council through the Additive Manufacturing Centre Initiative (SERC Grant No 14268 00088). 


\section{REFERENCES}

1. Brockmann W. Adhesive bonding : materials, applications and technology. Brockmann W, editor. Weinheim: Wiley-VCH; 2009.

2. Baldan A. Adhesion phenomena in bonded joints. International Journal of Adhesion and Adhesives. 2012;38(0):95-116.

3. Graham D.P. RA, Baker D., Smith P.A, Watts J.F. A Hybrid Joining Scheme For HighStrength Multi-Material Joints. Proceedings of 18th International Conference on Composite Materials; South Korea2011.

4. Heimbs S, Nogueira AC, Hombergsmeier E, May M, Wolfrum J. Failure behaviour of composite T-joints with novel metallic arrow-pin reinforcement. Composite Structures. 2014;110(0):16-28.

5. Kashaev N, Ventzke V, Riekehr S, Dorn F, Horstmann M. Assessment of alternative joining techniques for Ti-6Al-4V/CFRP hybrid joints regarding tensile and fatigue strength. Materials \& Design. 2015;81:73-81.

6. Philip NP, Richard B, Darryl A. Growth of Damage in Additively Manufactured Metal-Composite Joints. Proceedings of 15th European Conference on Composite Materials; Venice Italy2012.

7. Philip NP, Richard B, Darryl A. Fatigue of Metal-Composite Joints with Penetrative Reinforcement. 54th AIAA/ASME/ASCE/AHS/ASC Structures, Structural Dynamics, and Materials Conference. Structures, Structural Dynamics, and Materials and Co-located Conferences: American Institute of Aeronautics and Astronautics; 2013.

8. Tu W, Wen PH, Hogg PJ, Guild FJ. Optimisation of the protrusion geometry in Comeld $^{\mathrm{TM}}$ joints. Composites Science and Technology. 2011;71(6):868-76.

9. Ucsnik S, Scheerer M, Zaremba S, Pahr DH. Experimental investigation of a novel hybrid metal-composite joining technology. Composites Part A: Applied Science and Manufacturing. 2010;41(3):369-74.

10. Wang X, Ahn J, Kaboglu C, Yu L, Blackman BRK. Characterisation of compositetitanium alloy hybrid joints using digital image correlation. Composite Structures. 2016;140:702-11.

11. Parkes PN, Butler R, Meyer J, de Oliveira A. Static strength of metal-composite joints with penetrative reinforcement. Composite Structures. 2014;118(0):250-6.

12. Nguyen ATT, Brandt M, Orifici AC, Feih S. Hierarchical surface features for improved bonding and fracture toughness of metal-metal and metal-composite bonded joints. International Journal of Adhesion and Adhesives. 2016;66:81-92.

13. Mouritz AP. Review of z-pinned composite laminates. Composites Part A: Applied Science and Manufacturing. 2007;38(12):2383-97. 
14. Cartié DDR, Cox BN, Fleck NA. Mechanisms of crack bridging by composite and metallic rods. Composites Part A: Applied Science and Manufacturing. 2004;35(11):1325-36.

15. Chang P, Mouritz AP, Cox BN. Properties and failure mechanisms of z-pinned laminates in monotonic and cyclic tension. Composites Part A: Applied Science and Manufacturing. 2006;37(10):1501-13.

16. Dai S-C, Yan W, Liu H-Y, Mai Y-W. Experimental study on z-pin bridging law by pullout test. Composites Science and Technology. 2004;64(16):2451-7.

17. Aslani F, Nejadi S. Bond characteristics of steel fiber and deformed reinforcing steel bar embedded in steel fiber reinforced self-compacting concrete (SFRSCC). centeurjeng. 2012;2(3):445-70.

18. Breitenbücher R, Meschke G, Song F, Zhan Y. Experimental, analytical and numerical analysis of the pullout behaviour of steel fibres considering different fibre types, inclinations and concrete strengths. Structural Concrete. 2014;15(2):126-35.

19. Alwan JM, Naaman AE, Hansen W. Pull-out work of steel fibers from cementitious composites: Analytical investigation. Cement and Concrete Composites. 1991;13(4):247-55.

20. Lee Y, Kang S-T, Kim J-K. Pullout behavior of inclined steel fiber in an ultra-high strength cementitious matrix. Construction and Building Materials. 2010;24(10):2030-41.

21. Naaman A, Namur G, Alwan J, Najm H. Fiber Pullout and Bond Slip. I: Analytical Study. Journal of Structural Engineering. 1991;117(9):2769-90.

22. Mouritz AP. Environmental durability of z-pinned carbon fibre-epoxy laminate exposed to water. Composites Science and Technology. 2012;72(13):1568-74.

23. Sweeting RD, Thomson RS. The effect of thermal mismatch on Z-pinned laminated composite structures. Composite Structures. 2004;66(1-4):189-95.

24. Cartié DDR, Dell'Anno G, Poulin E, Partridge IK. 3D reinforcement of stiffener-toskin T-joints by Z-pinning and tufting. Engineering Fracture Mechanics. 2006;73(16):253240.

25. ASTM. Standard Test Method for Mode I Interlaminar Fracture Toughness of Unidirectional Fiber-Reinforced Polymer Matrix Composites. ASTM D5528-13. West Conshohocken: ASTM International; 2013.

26. Inam Ullah MB, Stefanie Fieh. Performance of bio-inspired Kagome truss core structures under compression and shear loading. COMPOSITE STRUCTURE. 2014;118:294-302.

27. Brandt M, Sun S, Leary M, Feih S, Elambasseril J, Liu Q. High-value SLM aerospace components: From design to manufacture. Advanced Materials Research. 2013;633:135-47. 
28. Mazur M, Leary M, Sun S, Vcelka M, Shidid D, Brandt M. Deformation and failure behaviour of Ti-6Al-4V lattice structures manufactured by selective laser melting (SLM). The International Journal of Advanced Manufacturing Technology. 2016;84(5):1391-411.

29. Simonelli M, Tse YY, Tuck C. Effect of the build orientation on the mechanical properties and fracture modes of SLM Ti-6Al-4V. Materials Science and Engineering: A. 2014;616:1-11.

30. Katalinic B, Hanzl P, Zetek M, Bakša T, Kroupa T. 25th DAAAM International Symposium on Intelligent Manufacturing and Automation, 2014The Influence of Processing Parameters on the Mechanical Properties of SLM Parts. Procedia Engineering. 2015;100:1405-13.

31. Strano G, Hao L, Everson RM, Evans KE. Surface roughness analysis, modelling and prediction in selective laser melting. Journal of Materials Processing Technology. 2013;213(4):589-97.

32. Dávila C, Rose C, Camanho P. A procedure for superposing linear cohesive laws to represent multiple damage mechanisms in the fracture of composites. Int $\mathrm{J}$ Fract. 2009;158(2):211-23.

33. Plain KP, Tong L. Experimental validation of theoretical traction law for inclined through-thickness reinforcement. Composite Structures. 2009;91(2):148-57.

34. Song MC, Sankar BV, Subhash G, Yen CF. Analysis of mode I delamination of zpinned composites using a non-dimensional analytical model. Composites Part B: Engineering. 2012;43(4):1776-84.

35. ABAQUS Version 6.10 Documentation Collection 2011 [updated April 20th].

36. Turon A, Dávila CG, Camanho PP, Costa J. An engineering solution for mesh size effects in the simulation of delamination using cohesive zone models. Engineering Fracture Mechanics. 2007;74(10):1665-82.

37. Grassi M, Zhang X. Finite element analyses of mode I interlaminar delamination in zfibre reinforced composite laminates. Composites Science and Technology. 2003;63(12):1815-32.

38. Yan W, Liu H-Y, Mai Y-W. Numerical study on the mode I delamination toughness of z-pinned laminates. Composites Science and Technology. 2003;63(10):1481-93.

39. Kravchenko S, Kravchenko O, Wortmann M, Pietrek M, Horst P, Pipes RB. Composite toughness enhancement with interlaminar reinforcement. Composites Part A: Applied Science and Manufacturing. 2013;54:98-106.

40. Bianchi F, Zhang X. A cohesive zone model for predicting delamination suppression in z-pinned laminates. Composites Science and Technology. 2011;71(16):1898-907. 
41. Dantuluri V, Maiti S, Geubelle PH, Patel R, Kilic H. Cohesive modeling of delamination in Z-pin reinforced composite laminates. Composites Science and Technology. 2007;67(3-4):616-31.

42. Mouritz AP, Koh TM. Re-evaluation of mode I bridging traction modelling for $\mathrm{z}$ pinned laminates based on experimental analysis. Composites Part B: Engineering. 2014;56(0):797-807.

43. $\mathrm{Li} \mathrm{C}, \mathrm{Wu} \mathrm{Z}$, Meng Z, Li M. Influential Factors of Z-pin Bridging Force. Appl Compos Mater. 2014;21(4):615-31.

44. Allegri G, Yasaee M, Partridge IK, Hallett SR. A novel model of delamination bridging via Z-pins in composite laminates. International Journal of Solids and Structures. 2014;51(19-20):3314-32.

45. Knaupp M, Baudach F, Franck J, Scharr G. Mode I and pull-out tests of composite laminates reinforced with rectangular z-pins. Journal of Composite Materials. 2014;48(23):2925-32.

46. Cui H, Li Y, Koussios S, Zu L, Beukers A. Bridging micromechanisms of Z-pin in mixed mode delamination. Composite Structures. 2011;93(11):2685-95.

47. Pegorin F, Pingkarawat K, Daynes S, Mouritz AP. Influence of Z-pin length on the delamination fracture toughness and fatigue resistance of pinned composites. Composites Part B: Engineering. 2015(0).

48. Pingkarawat K, Mouritz AP. Improving the mode I delamination fatigue resistance of composites using z-pins. Composites Science and Technology. 2014;92:70-6.

49. Pingkarawat K, Mouritz AP. Comparative study of metal and composite z-pins for delamination fracture and fatigue strengthening of composites. Engineering Fracture Mechanics. 2016;154:180-90.

50. Group AC. ACG VTM 260 Series2006. Available from: http://www.lavenderce.com/wp-content/uploads/pds1154-vtm260-issue5.pdf. 
Table 1: Specimen configurations

\begin{tabular}{cccc}
\hline Test type & $D[\mathrm{~mm}]$ & $L[\mathrm{~mm}]$ & Pin volume [\%] \\
\hline Single pin & 0.50 & 2 & -- \\
Single pin & 0.50 & 3 & -- \\
Single pin & 0.50 & 4 & -- \\
Single pin & 1.00 & 3.5 & -- \\
\hline DCB & -- & -- & -- \\
DCB & 0.50 & 2 & 0.5 \\
DCB & 0.50 & 4 & 0.5 \\
\hline
\end{tabular}

Table 2: Material properties of VTM264 ${ }^{(50)}$ and Ti-6Al-4V $V^{(27)}$. E and $G$ are elastic and shear modulus; $v$ is Poisson ratio; subscripts 1,2,3 are directions in a ply-based coordinate system of fibre, in-plane transverse and out-of-plane transverse, respectively; $X_{T}, Z_{T}$ and $S_{12}$ are inplane tension, out-of-plane tension and in-plane shear strength; $t_{p l y}$ is thickness of the composite ply.

\begin{tabular}{cccc}
\hline \multicolumn{2}{c}{ VTM264 } & \multicolumn{2}{c}{ Ti-6Al-4V } \\
\hline$E_{11}(\mathrm{MPa})$ & 120000 & $E(\mathrm{MPa})$ & 110000 \\
$E_{22}(\mathrm{MPa})$ & 7500 & $G(\mathrm{MPa})$ & 42500 \\
$E_{33}(\mathrm{MPa})$ & 7500 & $v$ & 0.32 \\
$G_{12}(\mathrm{MPa})$ & 3900 & & \\
$G_{13}(\mathrm{MPa})$ & 3900 & & \\
$G_{23}(\mathrm{MPa})$ & 2300 & & \\
$v_{12}$ & 0.32 & & \\
$X_{T}(\mathrm{MPa})$ & 2459 & & \\
$Z_{T}(\mathrm{MPa})$ & 45 & & \\
$S_{12}(\mathrm{MPa})$ & 85 & & \\
$t_{\mathrm{ply}}(\mathrm{mm})$ & 0.21 & & \\
\hline
\end{tabular}


Table 3: Cohesive model parameters

\begin{tabular}{lccc}
\hline \multirow{2}{*}{ Cohesive model parameter } & \multicolumn{3}{c}{ Metal-Composite joint } \\
& Resin Fracture & Fibre Bridging & Composite \\
\hline Normal Strength $t_{n}(\mathrm{MPa})$ & $42.2^{(1)}$ & $1.3^{(1)}$ & $44.5^{(1)}$ \\
Normal Fracture Energy $G_{\mathrm{IC}}\left(\mathrm{J} / \mathrm{m}^{2}\right)$ & $200^{(1)}$ & $800^{(1)}$ & $1000^{(1)}$ \\
Maximum Normal Displacement $\delta(\mathrm{mm})$ & -- & $6.6^{(1)}$ & \\
Mixed-mode exponent $\alpha$ & -- & $11^{(2)}$ & \\
Normal Penalty Stiffness $K_{n}(\mathrm{MPa})$ & $35700^{(2)}$ & $35700^{(2)}$ & \\
Shear Strength $t_{s}(\mathrm{MPa})$ & $81^{(1)}$ & $4^{(2)}$ & $85^{(3)}$ \\
Shear Fracture Energy $G_{\mathrm{IIC}}\left(\mathrm{J} / \mathrm{m}^{2}\right)$ & $1100^{(2)}$ & $1650^{(2)}$ & $2750^{(3)}$ \\
Shear Penalty Stiffness $K_{s}(\mathrm{MPa})$ & $35700^{(2)}$ & $35700^{(2)}$ & \\
Power law coefficient $\eta$ & $1.21^{(3)}$ & $1.21^{(3)}$ & \\
\hline (1) Calculated from experimental data; (2) Calibrated to fit with experimental data;(3) Based on literature data &
\end{tabular}

Table 4: Single pin specimens, experimental results

\begin{tabular}{lcccc}
\hline & $D=0.5, L=2$ & $D=0.5, L=3$ & $D=0.5, L=4$ & $D=1.0, L=3.5$ \\
\hline$L / D$ Nominal & 4 & 6 & 8 & 3.5 \\
$L / D$ Actual & 3.3 & 5.0 & 6.5 & 3.3 \\
$C_{e}$, mm & 1.93 & 1.93 & 1.93 & 3.30 \\
Failure mode & Interface & Pin & Pin & Interface \\
$P_{\max }, \mathrm{N}(\mathrm{COV})$ & $189(9 \%)$ & $212(14 \%)$ & $207(15 \%)$ & $567(7 \%)$ \\
$\Delta_{0}, \mathrm{~mm}(\mathrm{COV})$ & $0.062(25 \%)$ & $0.055^{*}(6 \%)$ & $0.044(23 \%)$ & $0.071(13 \%)$ \\
Failure energy, J (COV) & $99.8(4 \%)$ & $17.0^{*}(7 \%)$ & $18.4(38 \%)$ & $432(6 \%)$ \\
$\sigma_{\max }, \mathrm{MPa}$ & - & 731 & 715 & - \\
$\tau_{\max }, \mathrm{MPa}$ & 50.7 & - & - & 49.9 \\
\hline
\end{tabular}

* 1 result excluded as an outlier 
Figure 1: Sample metal-composite fitting, incorporating (a) bolts or (b) through-thickness reinforcement pins

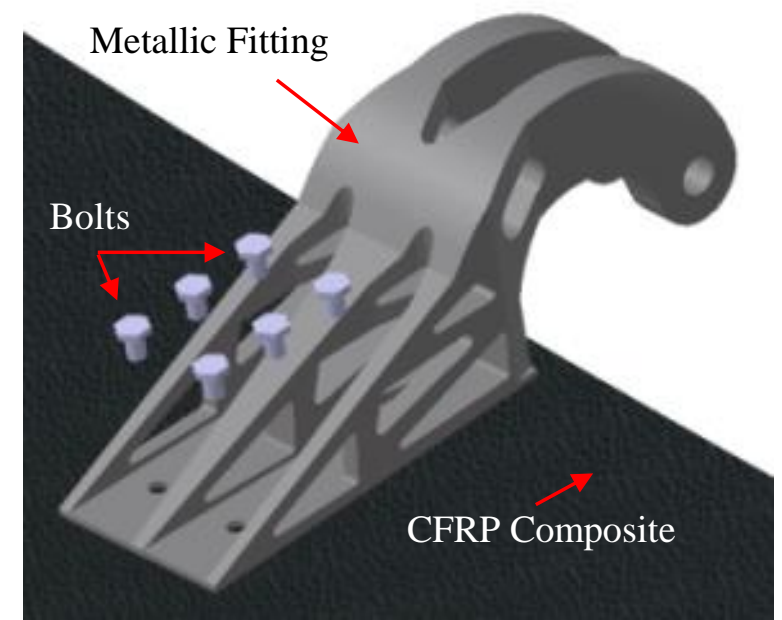

(a)

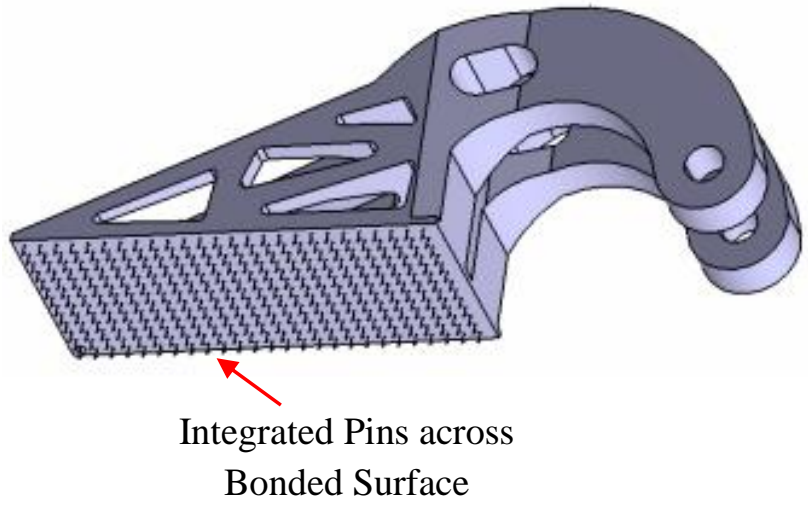

(b) 
Figure 2: Pull-out test setup of a single pin specimen with detail cross-section schematic
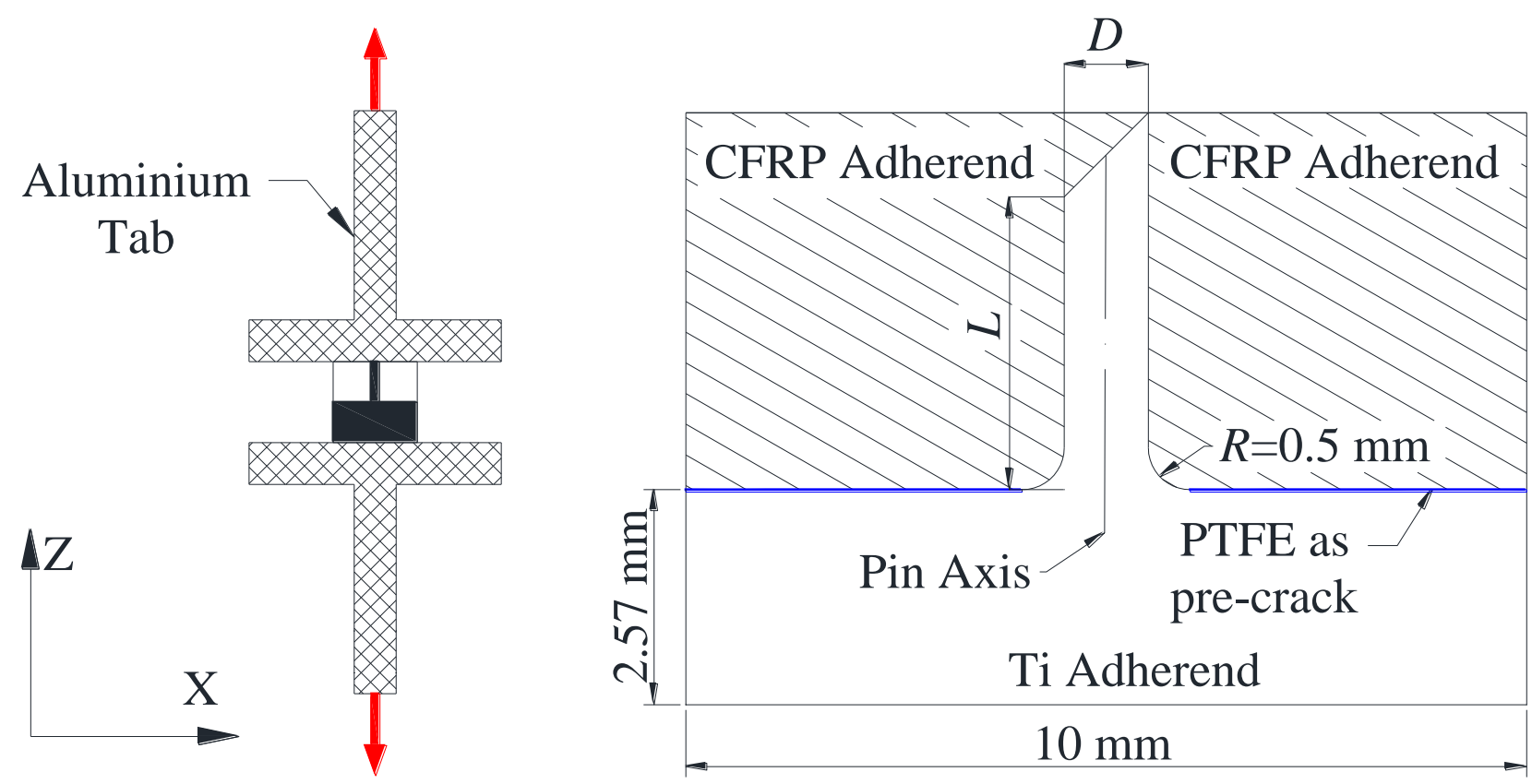
Figure 3: Double Cantilever Beam specimen

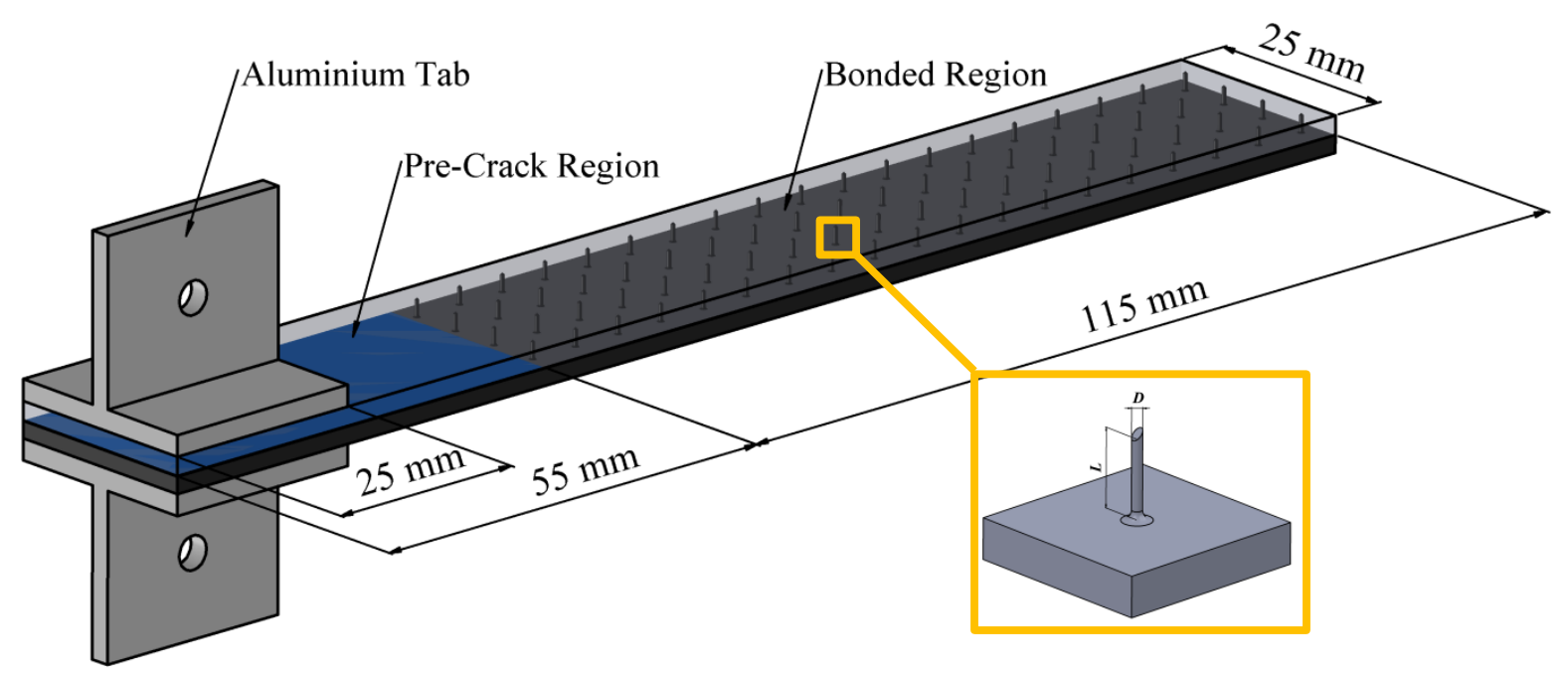


Figure 4: SLM manufacture. (a) Partially melted particles. (b) Average of measured dimensions (in mm) for $D=0.5$ (inner profile) and $D=1.0$. (c) Sample pin cross-section.

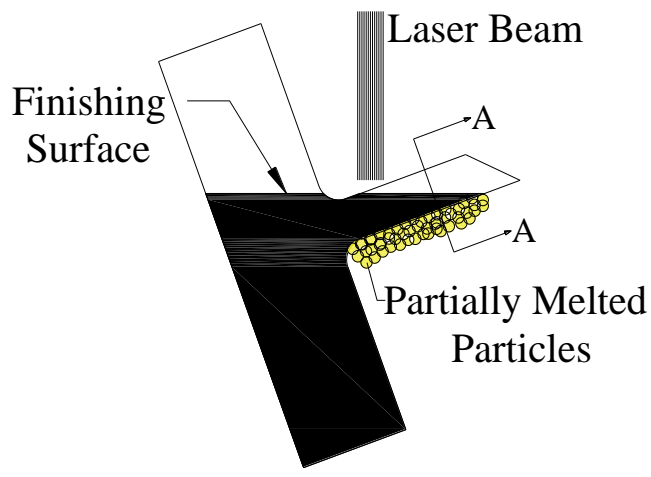

(a)

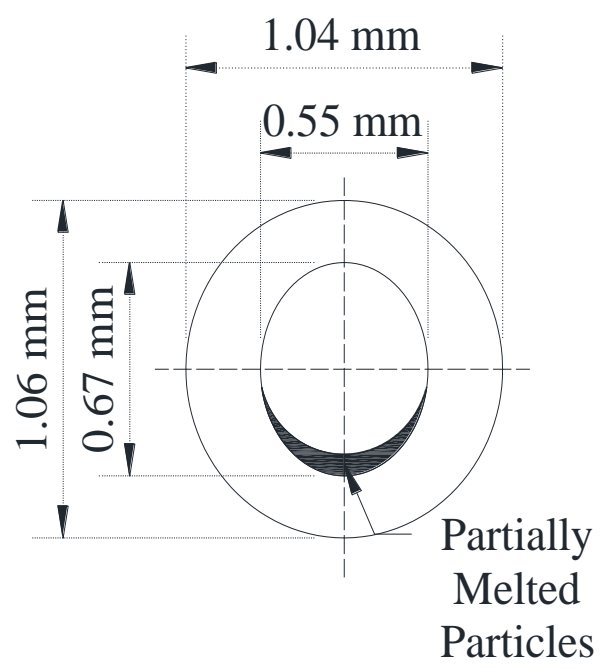

(b)

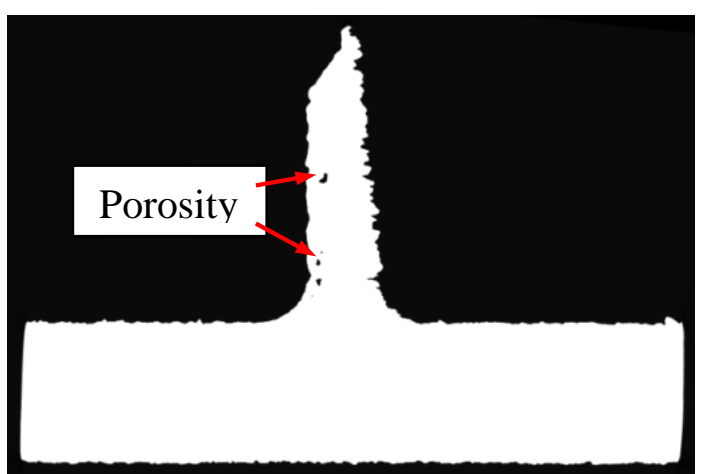

(c) 
Figure 5: Overall analysis methodology

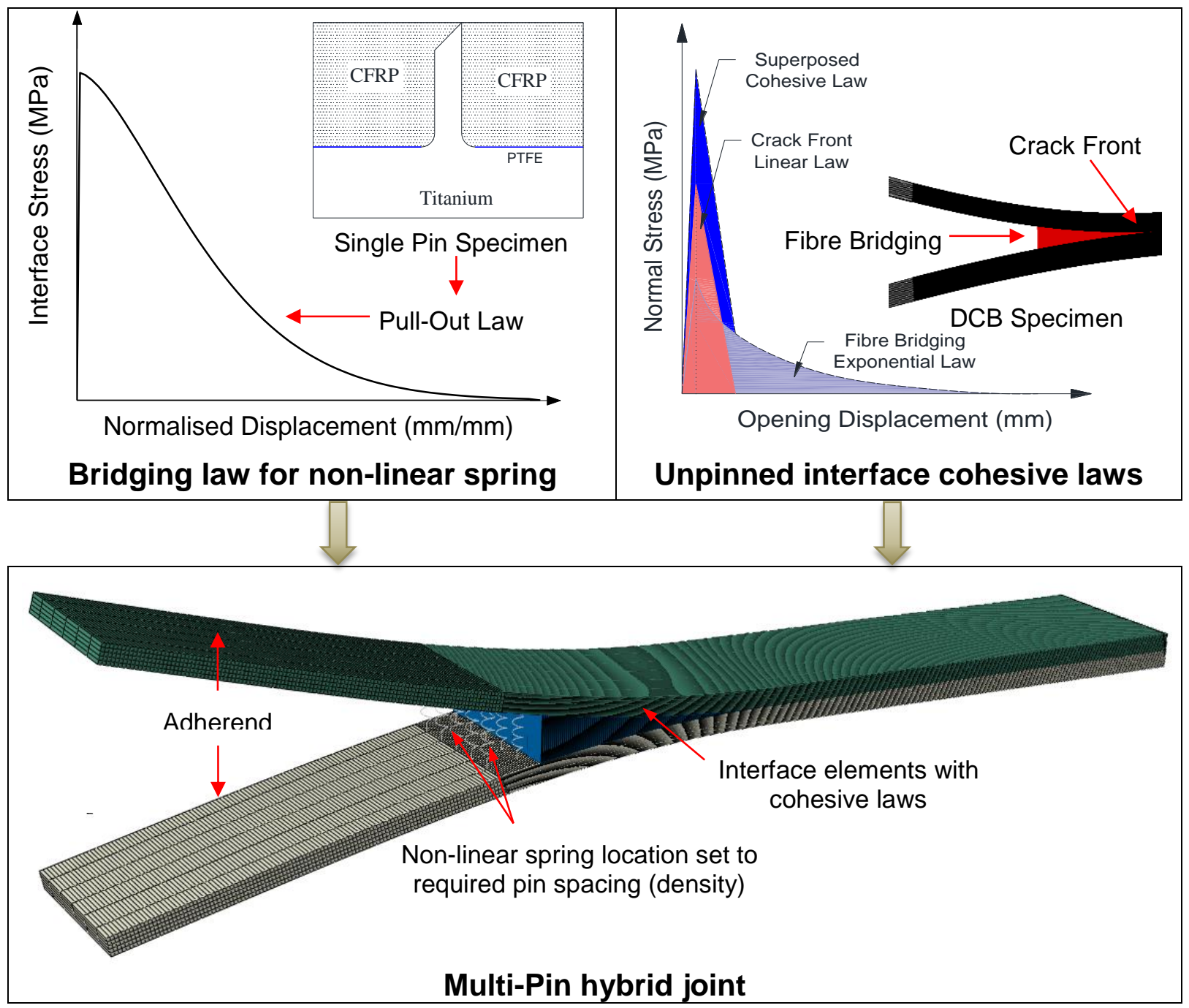


Figure 6: DCB FE modelling scheme and representative elements of damage mechanisms during crack propagation process

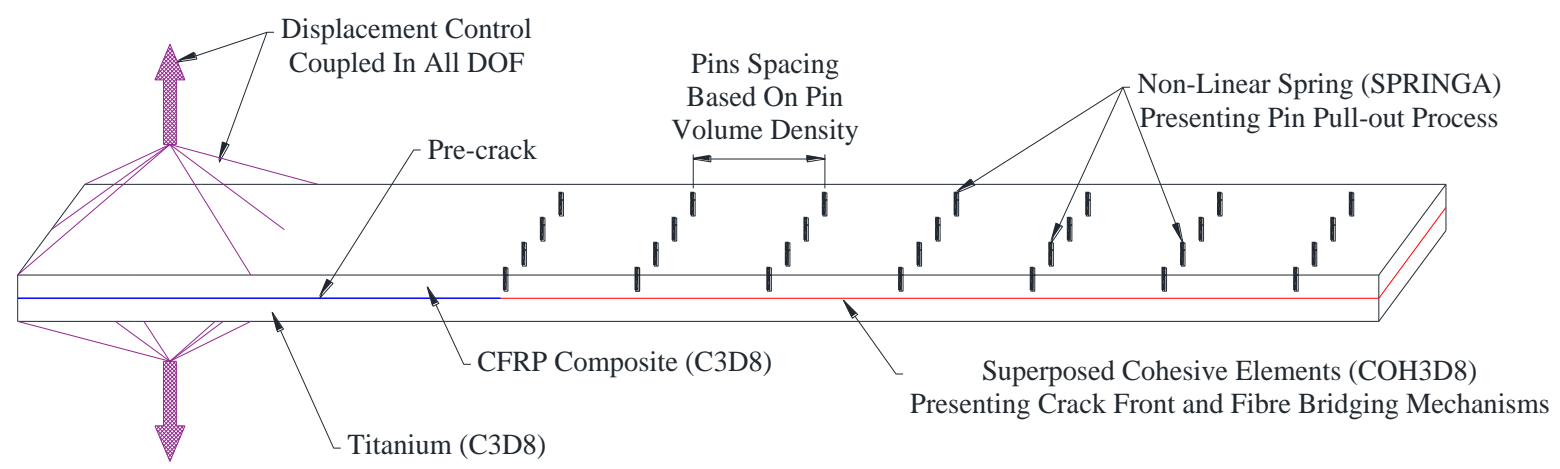


Figure 7: Cross-section schematics. (a) In-plane $(X Y)(b)$ BB: through-thickness parallel to fibres (XZ). (c) CC: through-thickness perpendicular to fibres (YZ).

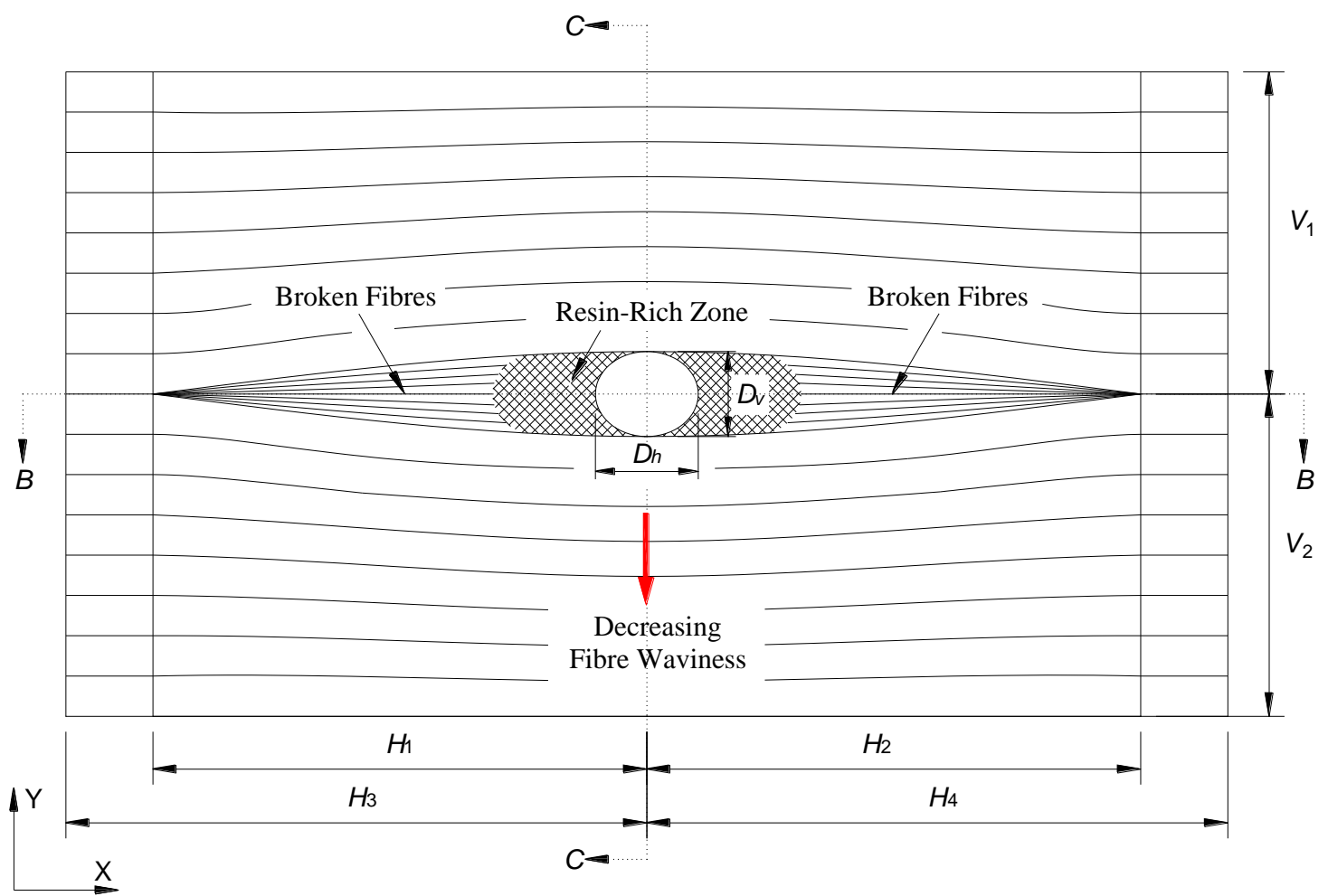

(a)

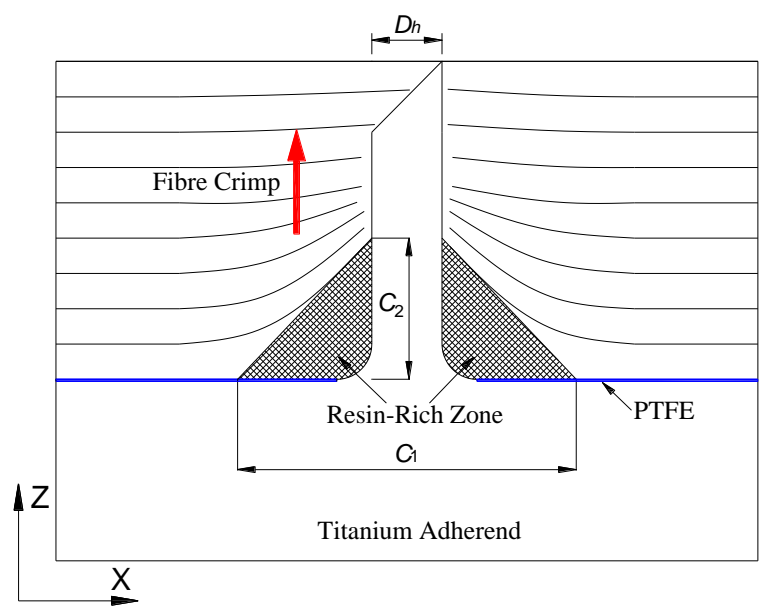

(b)

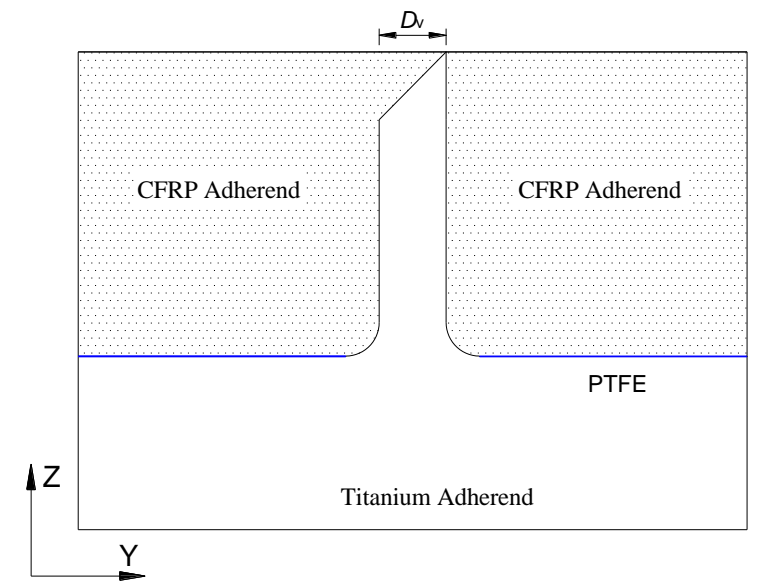

(c) 
Figure 8: Pin $(0.5 \mathrm{~mm})$ embedded in CFRP composite highlighting elliptical pin surface area and mechanical interlocking with surrounding resin: (a) In-plane cross-section with finishing surface on the left and (b) through-thickness cross-section.

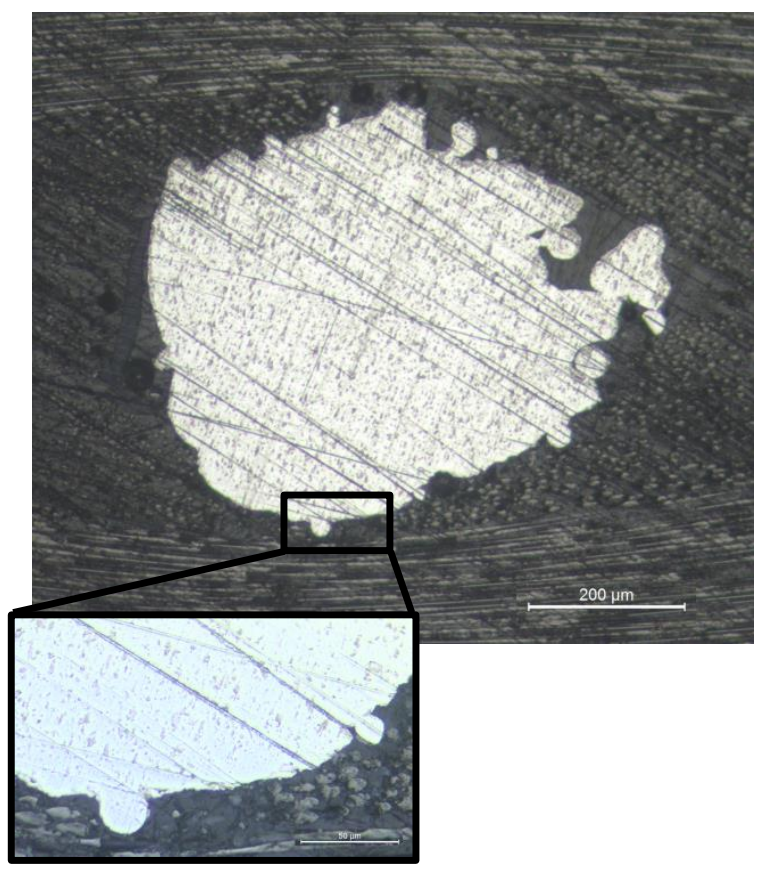

(a)

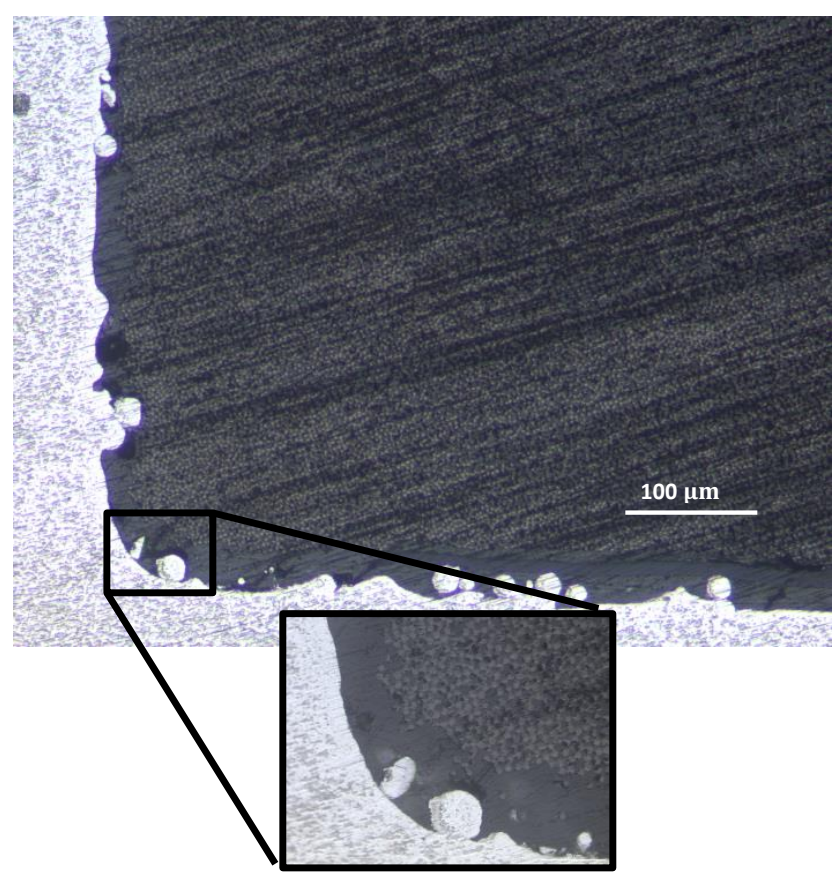

(b) 
Figure 9: Single pin specimens, load versus pull-out displacement

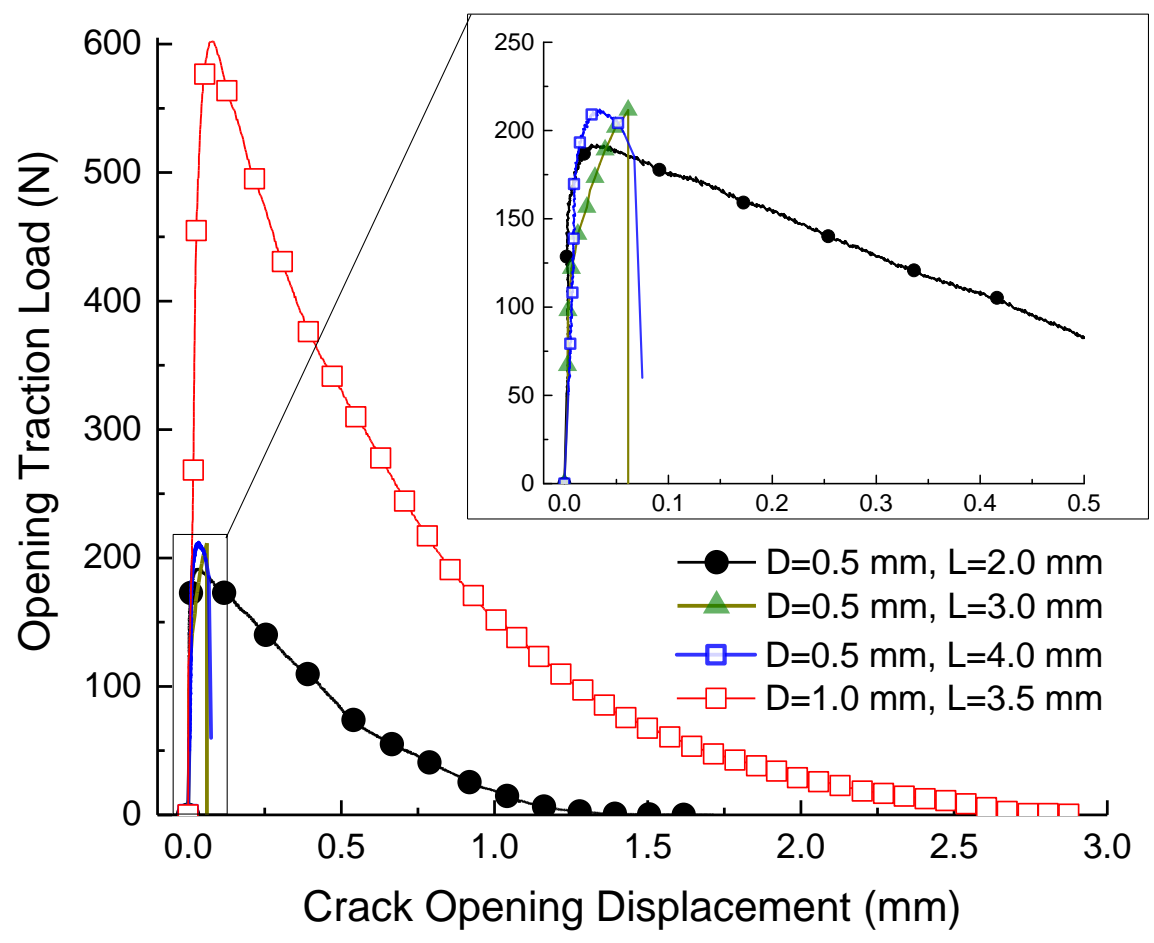


Figure 10: Specimens following interface failure. (a) Microscopy images of pin. (b) CT scan of pin cavity in composite adherend with only titanium set to be visible.
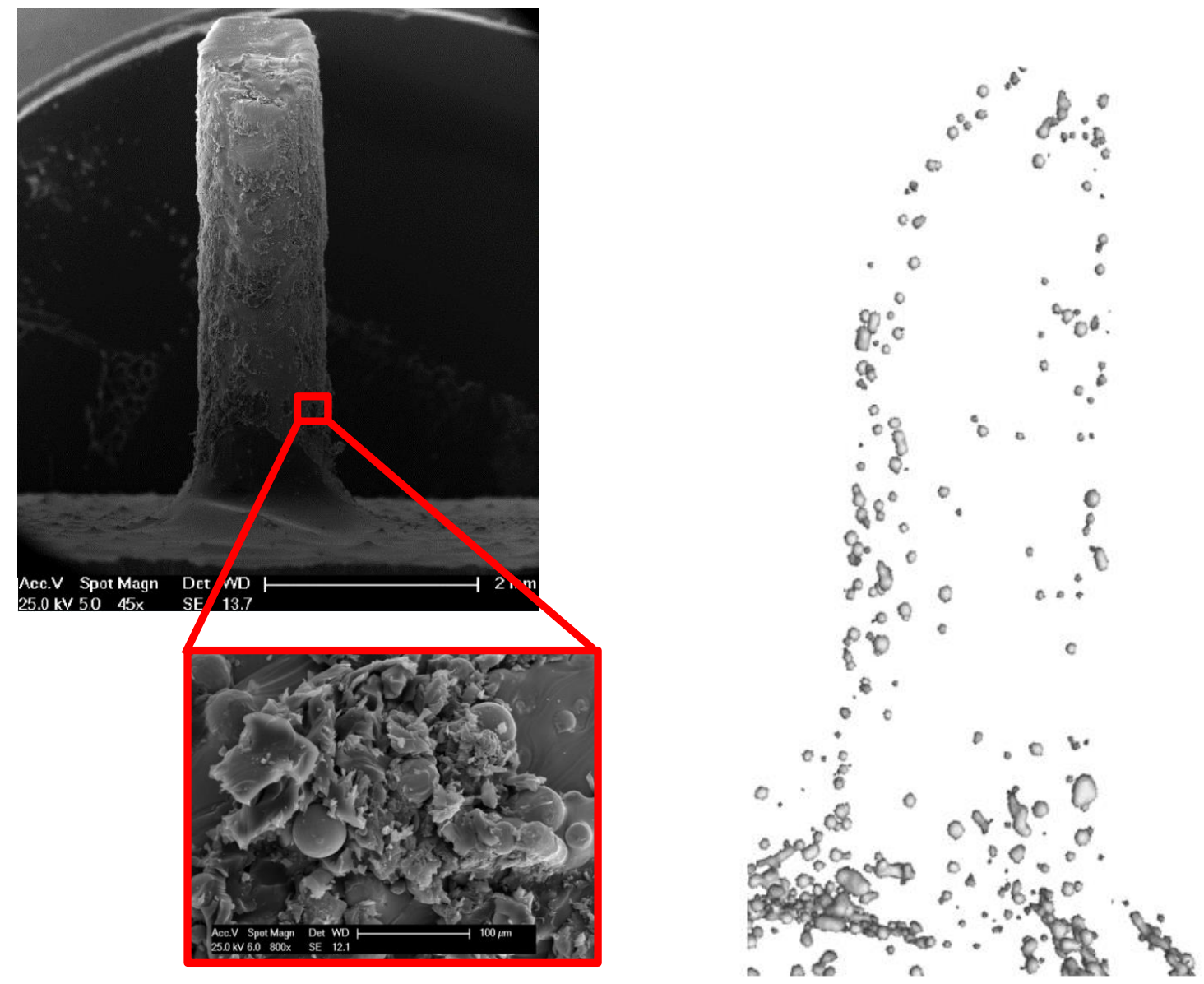
Figure 11: Illustration of pin fracture near root fillet. Embedded SLM powder particles at root clearly observed.

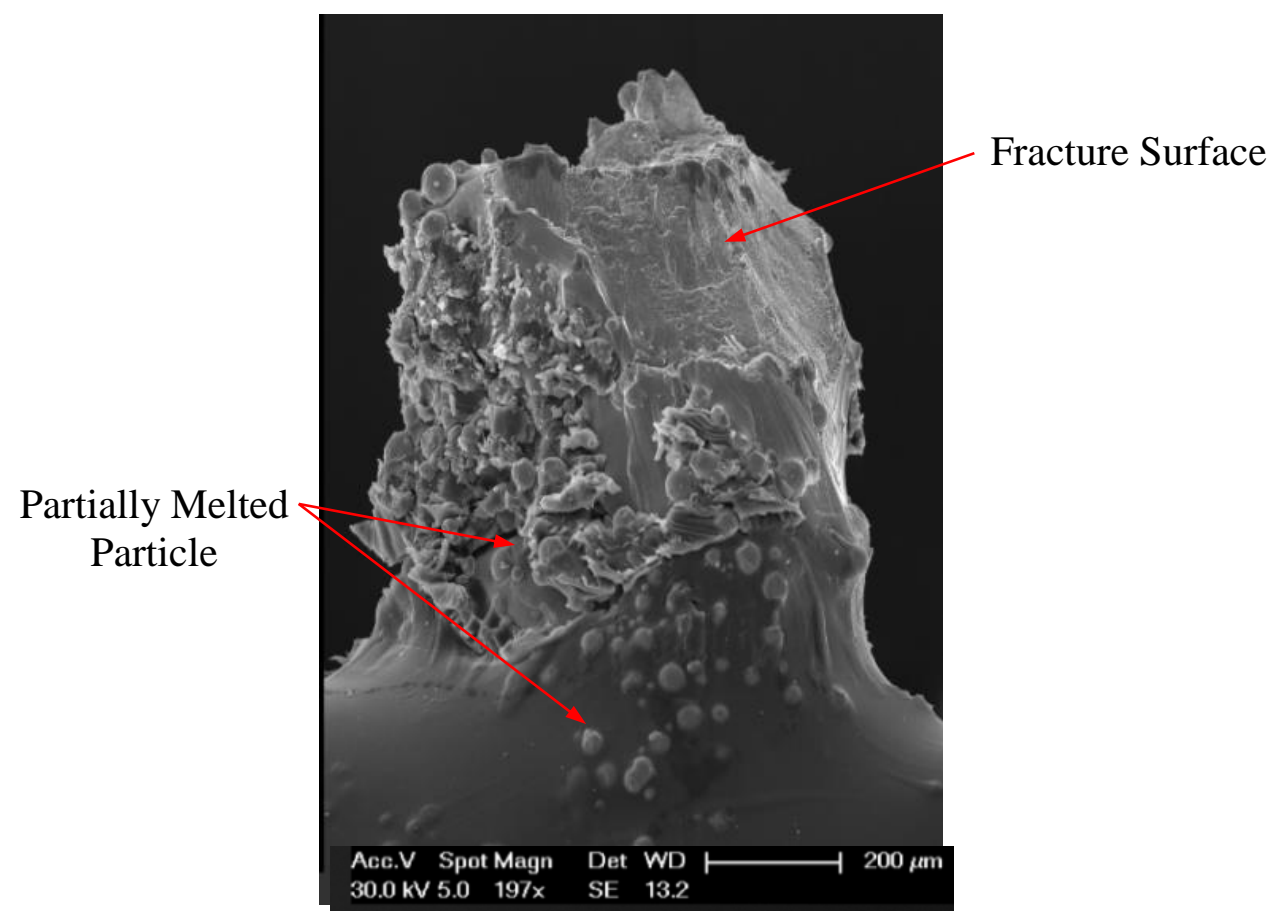


Figure 12: Interface stress versus normalised pull-out displacement, compared with typical zpin strength calculated based on study of Koh and Mouritz (42)

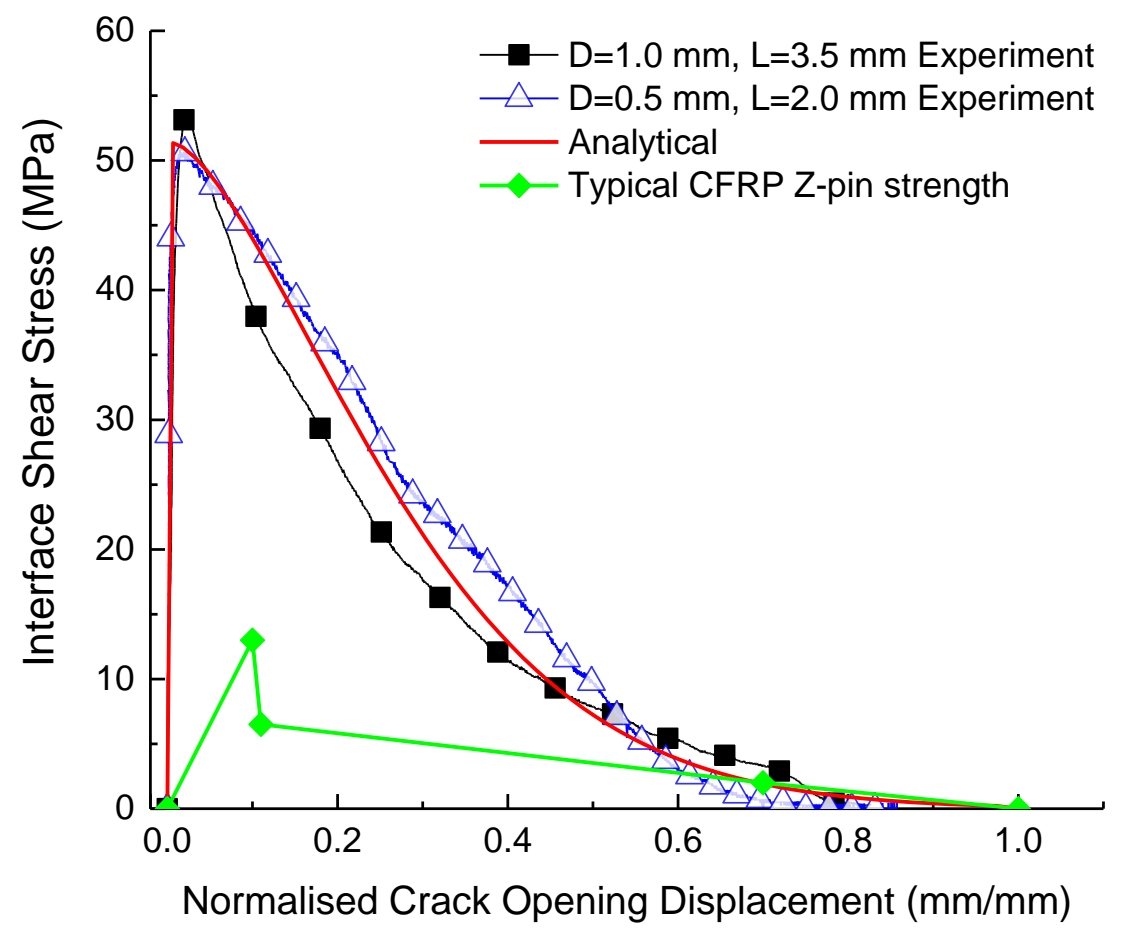


Figure 13: Contribution of pins with $2 \mathrm{~mm}$ length of varying volume density to DCB Mode I steady-state fracture toughness according to calculation based on Equation 8.

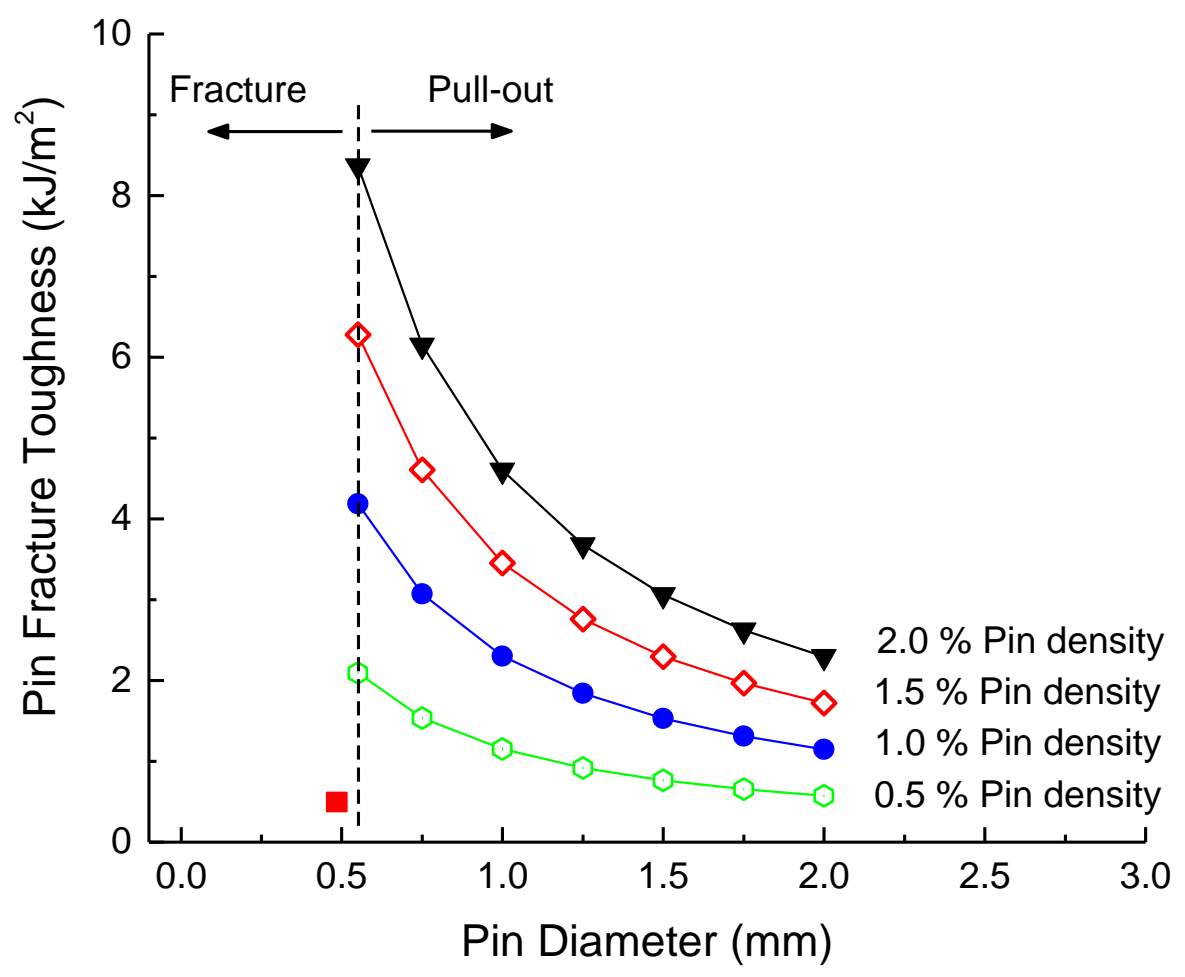


Figure 14: DCB specimens, unpinned ( $D=0)$, SLM pinned $(D=0.5, L=2),(D=0.5, L=4)$ and CFRP z-pin $(D=0.5, L=2)$ calculated based on study of Pingkarawat and Mouritz (48), experiment (solid lines) and numerical (dash lines) results. (a) Load-displacement. (b) $R$ curve.

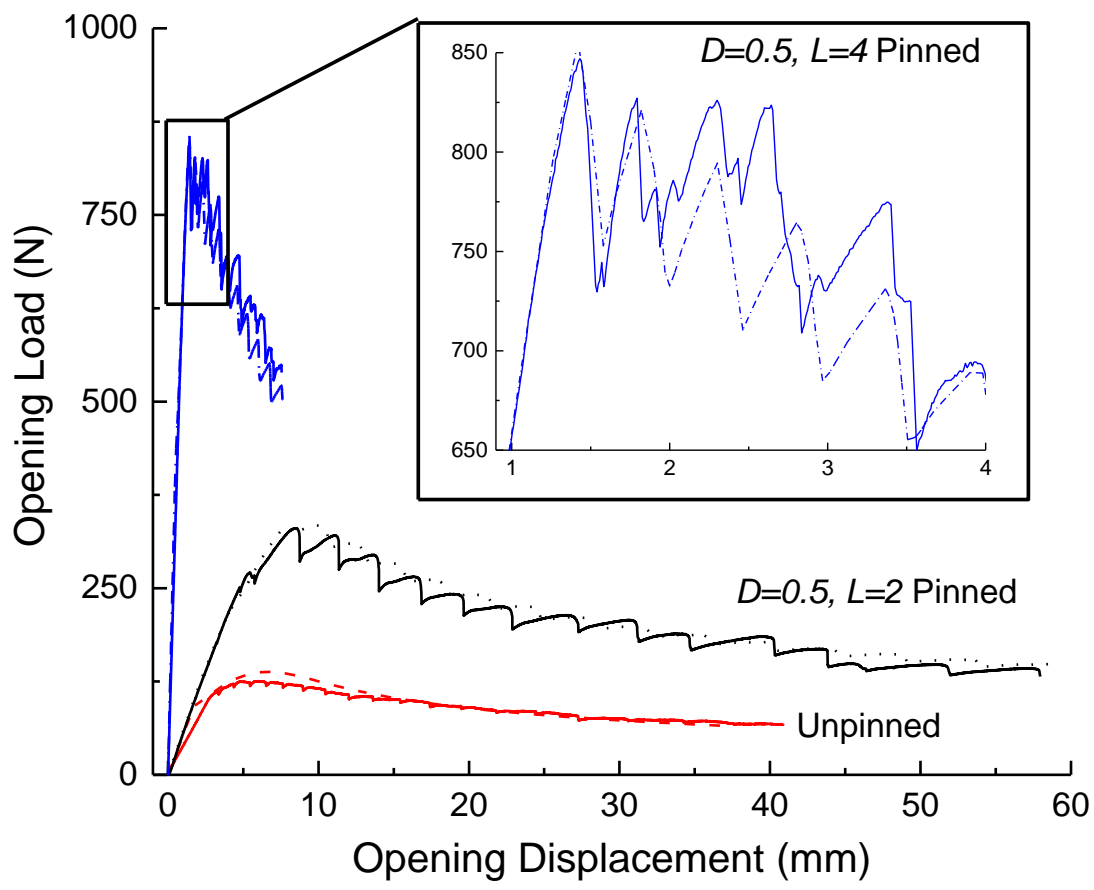

(a)

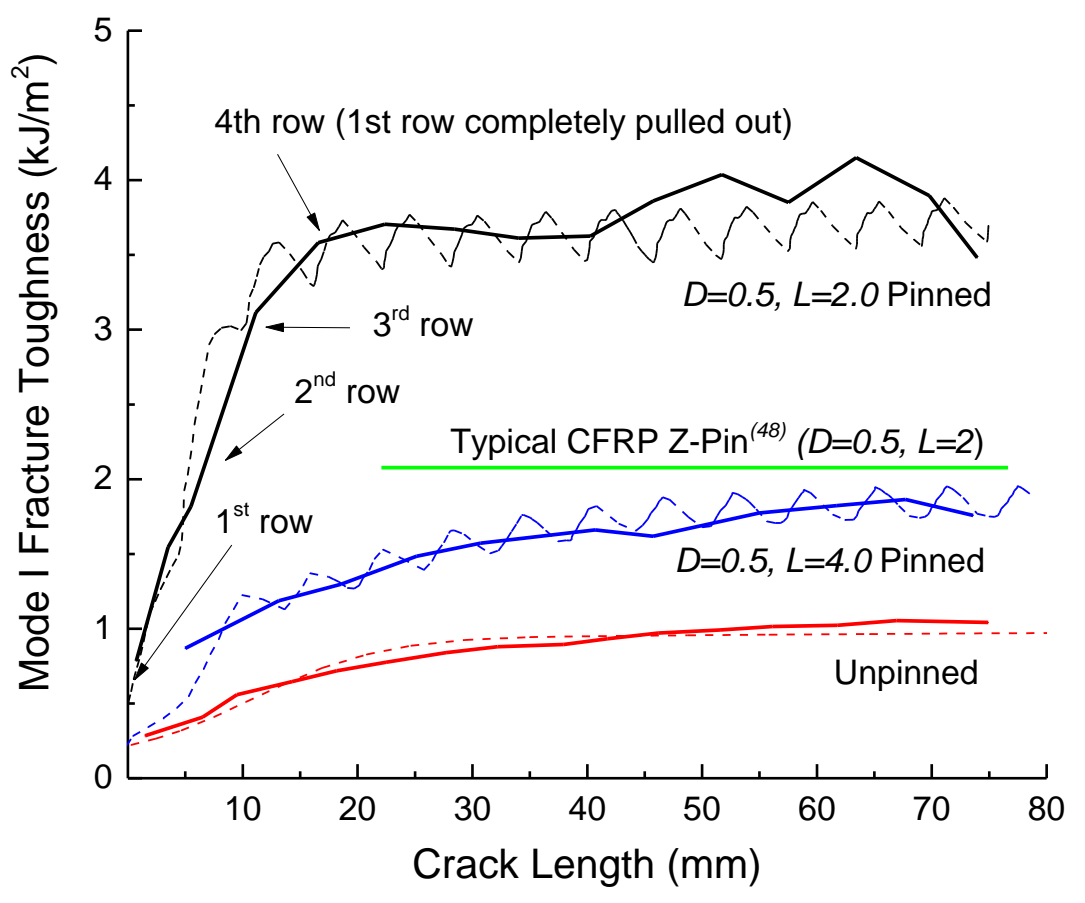

(b) 
Figure 15: DCB specimen features and damage mechanisms

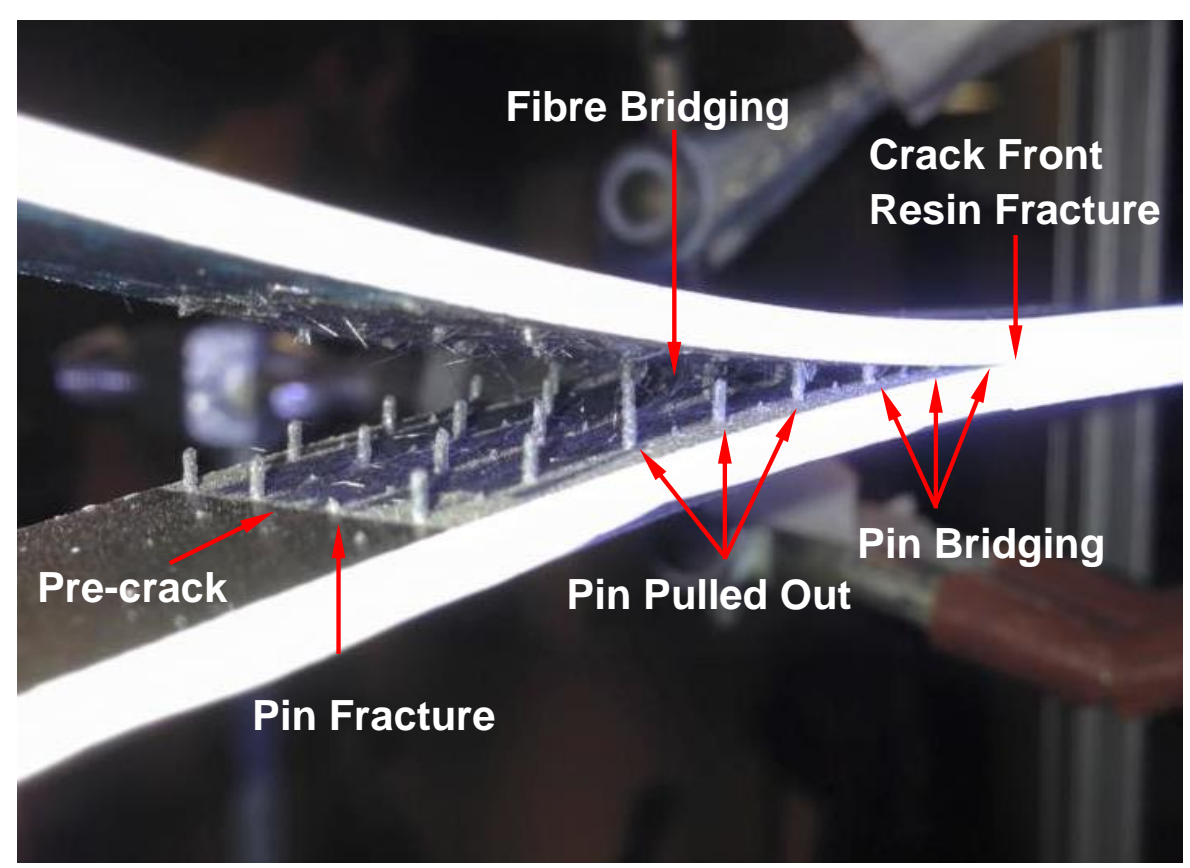


Figure 16: Detailed R-curve within the first 3 rows of pin of increasing pin interface strength

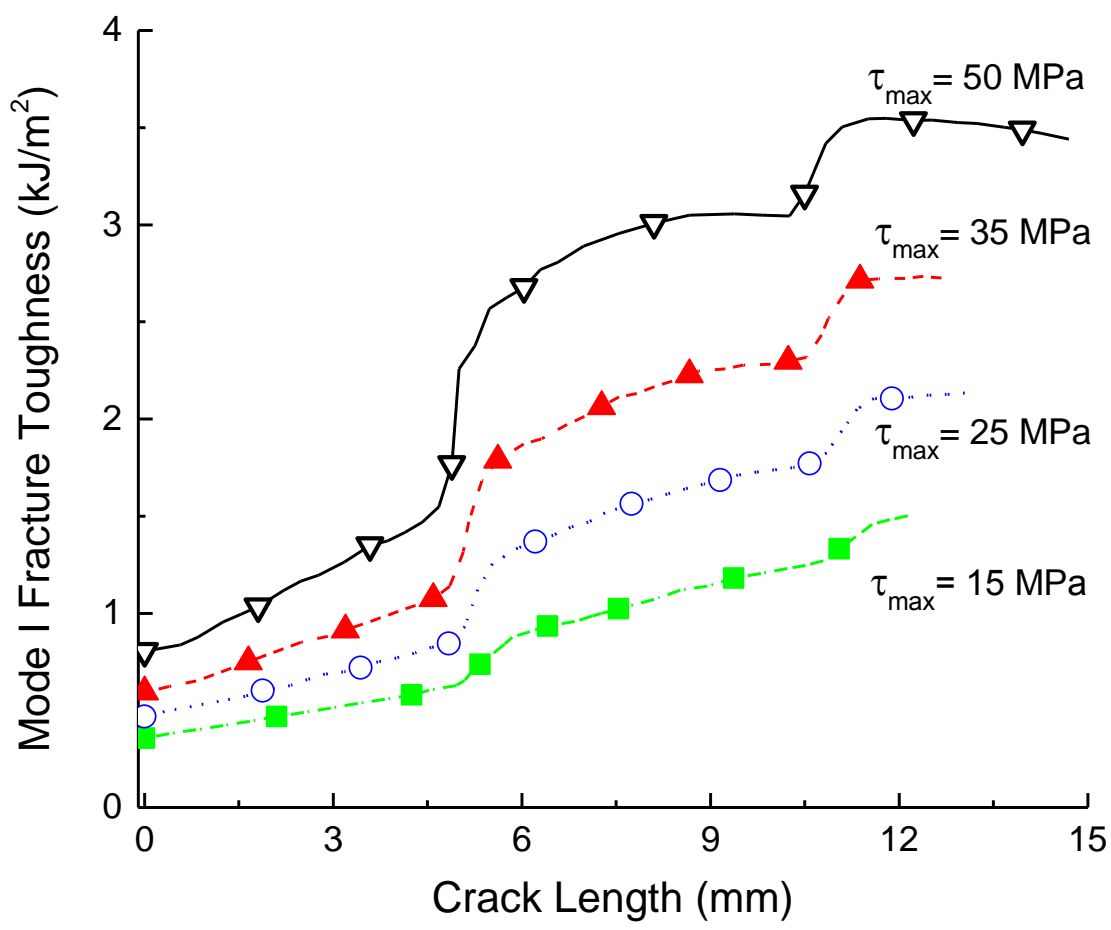

